\author{
Center \\ for \\ Economic Research
}

No. $2000-88$

THE EFFECTS OF ASYMMETRIC DEMOGRAPHIC SHOCKS WITH PERFECT CAPITAL MOBILITY

By Bas van Groezen and Theo Leers

September 2000

ISSN 0924-7815 


\title{
The Effects of Asymmetric Demographic Shocks with Perfect Capital Mobility
}

\author{
Bas van Groezen Theo Leers*
}

\begin{abstract}
In this paper we analyse the effects of asymmetric demographic shocks in a tworegion framework with perfectly mobile capital. Regions may differ in their individual thriftiness or the generosity of their social security arrangements. We find that population ageing in one region causes international spillover effects. Whether the ageing region is a net lender or not appears to be of significant importance. Both the short-run dynamics and the long-run effects of an asymmetric demographic shock are discussed. Special attention is paid to the welfare effects for the different generations residing in either region.
\end{abstract}

JEL classification: F21, F32, H55, J10

Keywords: population ageing, overlapping generations, pensions, capital mobility, dynamic analysis

*Department of Economics and CentER, Tilburg University, P.O. Box 90153, 5000 LE Tilburg, The Netherlands, e-mail: t.leers@kub.nl, phone: +31-134663255, fax: +31-134663042. The authors benefited from discussions with and suggestions from Lex Meijdam. The usual disclaimer applies. 


\section{Introduction}

In a globalising world where capital markets are further liberalised and integrated, economies are increasingly affected by developments that take place elsewhere. One such development is the ageing of the population that will occur in most industrialised countries in the upcoming decades. Because this demographic shift causes concerns about the feasibility of pension schemes that are financed on a Pay-As-YouGo (PAYG) basis, the transition to a funded pension scheme is much debated (see for example Feldstein [1996a]). However, not much attention has been paid to the open economy aspects of pension schemes, and in particular not to the effects of population ageing and the institutional design and generosity of intergenerational redistribution on international capital movements and the associated changes in factor rewards. Casarico (1999) investigates the effects of the integration of two large economies, running different pension schemes, in a world of perfect capital mobility. She finds that it is not trivial and straightforward to establish who gains and who loses. This is due to the short-run effects of this integration being different from the long-run implications. Furthermore, Shiller (1999) discusses the risk-sharing functions that governments have in designing social-security systems. Among other things, he compares alternative pension schemes in terms of their ability to fulfill the government's role in promoting international risk-sharing.

As Feldstein $(1974,1996 \mathrm{~b})$ pointed out, unfunded social security negatively impacts private savings. Because this reduces the capital stock, output per capita will be lower. Yet the extent to which the design and generosity of social-security arrangements thus impacts overall welfare strongly depends on both the size and the openness of the economy, as reflected in the degree to which capital can freely move across countries. A small open economy with a relatively large PAYG-scheme will merely run a current-account deficit as capital flows into the country. In a closed economy, though, a larger PAYG-scheme will negatively affect savings and thus push the interest rate up so that investments, and thereby the capital-labour ratio, decline. In case of two open economies and perfect capital mobility, the downward pressure of the PAYG-scheme on savings will also affect the other country. Because savings are lower in the country with a generous social-security scheme, capital is relatively scarce and would therefore earn a higher rate of return. This induces capital to move out of the country with a small PAYG-scheme, so this country ends up with a lower capital stock, and thus a lower level of output. Hence, the institutional characteristics of pension schemes cause international spillover effects that are likely to become more important as many countries will experience a higher relative number of pensioners and capital moves more freely between countries. This issue was also addressed by Pemberton (1999), which analyses the international externalities of social-security systems in a world consisting of many countries. A change in the savings of an individual country, e.g. caused by a more generous social-security scheme, hardly affects the world interest rate. Local governments do not take these spillover effects into 
account and consequently implement a too large PAYG-scheme. International policy coordination could therefore improve welfare.

This paper takes the size of the PAYG-scheme as given, and focuses on the effects of asymmetric demographic shocks on factor prices and welfare in a world consisting of countries whose capital markets are fully integrated. The model is an extension of Buiter (1981), which is based on the overlapping-generations model of Diamond (1965). As in Buiter (1981), we consider two regions. However, we also include a public pension scheme in both regions. In this aspect, we differ from Geide-Stevenson (1998) who analyses the connection between social-security policy and international factor movements within a world where one country runs a PAYG-public pension scheme and the other a fully funded private pension scheme. Contrary to GeideStevenson (1998) and Casarico (1999), we do not focus on the effects of integration, but on both the short-run and long-run implications of demographic shocks when both regions' (capital) markets are already fully integrated. Moreover, we distinguish between social-security arrangements with different intergenerational risk-sharing properties and investigate their impact on international risk-sharing.

In order to capture the fact that most OECD-countries are hit by population ageing at different moments and to a different degree $^{1}$, one region experiences a decline in the rate of population growth. In other words, one country ages relative to the other. In general, ageing causes two effects. First, a smaller labour force implies capital thickening, i.e., an increased capital stock per worker. Second, the dependency ratio rises, which means that total output per worker has to be shared with a larger number of pensioners.

Section 2 presents the model of this paper. In Section 3, we analyse the effects of a regional shock to the rate of population growth when individual thriftiness differs across regions and social security is absent. We find that the capital-labour ratio increases in the short run, but the long-run effects depend on the relative patience of the ageing country. If the population of the relatively patient country grows old, then the capital-labour ratio eventually falls. This is due to the average individual savings declining worldwide. Section 4 introduces PAYG-pension schemes. In Section 4.1, we find that in the long run, the impact of population ageing on the capital-labour ratio depends on the relative generosity of the regional social-security arrangements, as private savings are inversely related to the size of intergenerational redistribution. The extent to which population ageing impacts the economies depends on the intergenerational risk-sharing properties of the social-security scheme. The higher the degree of risk-sharing between generations, the more the effects of ageing appear to be confined. In particular, we show that sharing the burden and/or blessings of capital thickening between generations is of significant importance for the confining

${ }^{1}$ The United Nations (1998) record striking differences in the degree and moment of occurrence of population ageing in their World Population Prospects. For example, the increase in the dependency ratio over the next 40 years is much larger in Japan than in the USA. In Europe Italy appears to be the runner in front as far as population ageing is concerned. 
of the economic effects that population ageing brings about. In the short run, we distinguish between unexpected and anticipated demographic shocks. The short-run dynamics depend both on the relative size of the PAYG-scheme and its institutional design.

In Section 4.2 we analyse how relaxing some of our assumptions would change the main results. Section 5 concludes.

\section{The Model}

We apply a two-period overlapping-generations model of an open economy with no intrinsic uncertainty. Following Buiter (1981) and Thori (1996, Chapter 6), the world economy consists of two regions, the Domestic region and the Foreign region. These regions are denoted by the superscripts $D$ and $F$, respectively. Both are identical in every respect, except in taste, demographics, and the size of intergenerational redistribution. Production per young individual is described by a standard neoclassical constant-returns-to-scale production function, $f\left(k_{t}^{i}\right)$, where $k_{t}^{i}$ stands for the amount of capital per young individual in period $t$ in region $i, i=D, F{ }^{2}$ Perfect competition among producers gives the usual equilibrium conditions on the regional production factor markets, $r_{t}^{i}=f^{\prime}\left(k_{t}^{i}\right)$ and $w_{t}^{i}=f\left(k_{t}^{i}\right)-f^{\prime}\left(k_{t}^{i}\right) k_{t}^{i}$, where $r_{t}^{i}$ is the interest rate and $w_{t}^{i}$ denotes the corresponding wage rate in period $t$, in the respective region. Capital is perfectly mobile across regions, but labour is immobile. In particular, the following assumption holds.

Assumption I At any moment in time, any region is able to instantaneously adjust its capital stock by shifting capital from or to abroad.

This assumption implies that there are no (short-term) capital rigidities and the required amount of capital can immediately be obtained by importing or exporting capital. So, even if a region is unexpectedly hit by a (demographic) shock, the inhabitants will be able to adjust their stock of capital at once and any region will face the same rate of interest, i.e., $r_{t}^{D}=r_{t}^{F}=r_{t}, \forall t .^{3}$ As we assumed that both regions are endowed with the same production technology, we have $k_{t}^{D}=k_{t}^{F}=k_{t}$ and consequently $w_{t}^{D}=w_{t}^{F}=w_{t}$.

\footnotetext{
${ }^{2}$ The production function $f$ is assumed to be twice continuously differentiable; $f(0)=0 ; f^{\prime}(k) \equiv$ $\frac{\partial f}{\partial k}>0 ; f^{\prime \prime}(k) \equiv \frac{\partial^{2} f}{\partial k^{2}}<0 ; \lim _{k \rightarrow 0} f^{\prime}(k)=\infty ; \lim _{k \rightarrow \infty} f^{\prime}(k)=0$. Moreover, we assume that $\lim _{k \rightarrow 0}\left[-f^{\prime \prime}(k) k\right]>1$. This condition is stronger than the Inada-condition and is required for (local) stability of the steady-state equilibrium of our model (see Appendix B and Galor and Ryder [1989, p. 369]).

${ }^{3}$ For example, one might think of instantaneously movable capital as portable computers, transportable machinery and transferable private knowledge capital. Relaxing Assumption I means that one considers capital as machinery and factories, that cannot instantaneously be shipped from one region to another. The effects of (short-term) capital rigidities are discussed in Section 4.2.
} 
Both economies are populated by a large number of non-altruistic individuals with perfect foresight who live for two periods, such that in each period, both a young and an old generation are alive. Apart from age, individuals are identical. Young agents inelastically supply one unit of labour. Part of their gross wage income is taxed away by the local government via an exogenous lump-sum $\operatorname{tax}\left(\tau_{t}^{i}\right) ;{ }^{4}$ the remainder is either spent on consumption $\left(c_{t}^{i}\right)$ or is saved for old age $\left(s_{t}^{i}\right)$. Consequently, at any time $t$, first-period consumption is restricted by the following budget constraint,

$$
c_{t}^{i}=w_{t}-\tau_{t}^{i}-s_{t}^{i}, \quad i=D, F
$$

In the second period of their lives, the individuals are retired and entitled to a public pension benefit. They derive utility from old-age consumption $\left(z_{t+1}^{i}\right)$, which is financed from the return on first-period savings and the pension benefit $\left(\eta_{t+1}^{i}\right)$. The second-period budget constraint can thus be written as

$$
z_{t+1}^{i}=\left(1+r_{t+1}\right) s_{t}^{i}+\eta_{t+1}^{i}
$$

Lifetime utility of a representative individual in region $i$ is given by the following additively separable utility function, ${ }^{5}$

$$
U\left(c_{t}^{i}, z_{t+1}^{i}\right)=\log c_{t}^{i}+\frac{1}{1+\rho^{i}} \log z_{t+1}^{i},
$$

where $\rho^{i}>0$ stands for the (constant) pure rate of time preference of an individual from region $i$.

Local governments run their social-security systems as PAYG-schemes with, at any time $t$, the following (balanced) budget constraint,

$$
\eta_{t}^{i}=\left(1+n_{t-1}^{i}\right) \tau_{t}^{i}
$$

where $n_{t-1}^{i}$ is the one-period proportional rate of population growth in region $i$ at time $t-1$. So, the number of young individuals present in region $i$ during period $t, N_{t}^{i}$, equals $N_{0}^{i} \prod_{j=0}^{t}\left(1+n_{j}^{i}\right)$, where $N_{0}^{i}$ is the initial population size in region $i$. Throughout the paper, we assume both economies to be dynamically efficient, i.e., $r_{t}>n_{t}^{i}, \forall t, i=D, F$.

\footnotetext{
${ }^{4}$ Applying a proportional tax rather than lump-sum taxation only affects the risk-sharing properties of the public pension schemes. For a discussion of proportional taxes as well as endogenous labour supply, it is referred to Section 4.2.

${ }^{5}$ We consider an additively separable utility function with logarithmic felicity functions for expositional clarity only. Our main results still hold if we assume the utility function $U$ to be twice continuously differentiable, strictly quasi-concave and increasing in its arguments. Furthermore, the Inada-conditions should apply.
} 
An individual maximises lifetime utility (3) subject to her single-period budget constraints (1) and (2). The optimal levels of first-period and second-period consumption are uniquely determined by the following first-order condition,

$$
z_{t+1}^{i}=\frac{1+r_{t+1}}{1+\rho^{i}} c_{t}^{i}
$$

From (5) it immediately follows that individual savings equal

$$
s_{t}^{i}=\frac{1}{2+\rho^{i}}\left(w_{t}-\tau_{t}^{i}\right)-\frac{1+\rho^{i}}{2+\rho^{i}} \frac{\eta_{t+1}^{i}}{1+r_{t+1}} .
$$

An increase in the net first-period income $\left(w_{t}-\tau_{t}^{i}\right)$ has a positive impact on the level of private savings; the same holds for an increase in the rate of interest, ${ }^{6}$ whereas a more generous PAYG-benefit $\left(\eta_{t+1}^{i}\right)$ influences savings negatively.

Domestic agents save by holding either domestic or foreign capital and are assumed not to suffer from a so-called home-bias or other factors that would impede capital flows. ${ }^{7}$ If the amount of net foreign capital owned by the domestic agents is positive (negative), the domestic region is a net lender (borrower). In our two-region framework, the capital exports of one region by definition equal the capital imports of the other region. In other words, at any time $t$, equilibrium on the financial market requires

$$
N_{t}^{D} s_{t}^{D}+N_{t}^{F} s_{t}^{F}=\left(N_{t+1}^{D}+N_{t+1}^{F}\right) k_{t+1} .
$$

Even if both regions are identical, there is international dependence due to the perfect capital mobility. Shifts in the domestic rate of population growth or changes in the design or generosity of the domestic social-security system can therefore have spillover effects on the foreign region. Furthermore, it directly follows from equation (7) that a region's aggregate savings can differ from the value of its capital stock because of the scope for international borrowing and lending (Buiter [1981, p. 782]). This allows countries to run a current-account surplus or deficit. In our simple framework, a region's current-account surplus (deficit) is exactly equal to its capital-account deficit (surplus). For a full description of the current account, which relates regional production to regional absorption, as well as a representation of other economic relations, it is referred to Appendix A.

We normalise the initial population size of both regions $\left(N_{0}^{D}=N_{0}^{F} \equiv 1\right)^{8}$ and we assume that the population in the foreign region is constant, $\left(n_{t}^{F}=0, \forall t\right)$. Let

\footnotetext{
${ }^{6}$ Due to our specification of the utility function the income effect and the substitution effect of a change in the interest rate exactly cancel out; a changing rate of interest only affects the net present value of the pension benefit and thereby savings.

${ }^{7}$ Such as capital controls, transactions costs, exchange rate risk and asymmetric information across countries (see for example Gordon and Bovenberg [1996]).

${ }^{8}$ Allowing for differences in initial population size among the regions does not affect the main results, except for the case where one of the regions is infinitely small relative to the other. This would imply a small open economy, for which it is referred to Appendix C.
} 
the population growth rate in the domestic region be equal to $n_{t}^{D}=n^{D}+\pi h_{t}$, where $n^{D} \equiv 0$ denotes the (initial) steady-state value of the domestic population growth rate, ${ }^{9} h_{t}$ describes the time pattern of a perturbation of this steady-state value and $\pi$ reflects its magnitude. The capital-accumulation equation (7) then reads as follows,

$$
\prod_{j=0}^{t}\left(1+\pi h_{j}\right) s_{t}^{D}+s_{t}^{F}=\left(\prod_{j=0}^{t+1}\left(1+\pi h_{j}\right)+1\right) k_{t+1} .
$$

In the initial steady state, this equation boils down to

$$
s^{D}+s^{F}=2 k .
$$

Given this setup, domestic ageing can be modeled as an unexpected (temporary) decrease in the domestic rate of population growth (i.e., at some time $t=0: h_{0}<0$, $h_{1}=h_{2}=\cdots=0$ ) or as an anticipated negative (temporary) shock at time $t=t^{*}$ that becomes publicly known at time $t=0$ (i.e., at some time $t^{*}>0: h_{0}=h_{1}=$ $\cdots=h_{t^{*}-1}=0, h_{t^{*}}<0, h_{t^{*}+1}=h_{t^{*}+2}=\cdots=0$, with $t^{*}$ finite). ${ }^{10}$ This distinction will appear to be of significance for the short-term effects of population ageing.

The effects of a marginal change in the domestic rate of population growth can be traced by the method of comparative dynamics, i.e., by linearising the capitalaccumulation equation (8) with respect to $\pi$ around the initial steady state. ${ }^{11}$ So the analysis of relative ageing of the domestic population in the subsequent sections will be based on a linearised version of the model presented above. In particular, the evolution of the capital-labour ratio as a result of demographic shocks is described by a linear first-order difference equation.

\section{Differences in Individual Thriftiness}

This section deals with the effects of ageing of the domestic population in a setting where the regions (initially) only differ in the individual thriftiness of their inhabitants. For the time being, we abstract from intergenerational redistribution $\left(\tau_{t}^{D}=\tau_{t}^{F}=0, \forall t\right)$. So, private savings are completely determined by the wage and the pure rate of time preference,

$$
s_{t}^{i}=\frac{1}{2+\rho^{i}} w_{t} .
$$

\footnotetext{
${ }^{9}$ By omitting time subscripts we denote the (initial) steady-state value of the respective variable.

${ }^{10}$ We only allow for temporary demographic shocks to avoid problems that will occur if one region grows infinitely large or small. We restrict ourselves to one-period shocks for expositional simplicity only; incorporation of multi-period shocks is straightforward. Note that a temporary decline in the rate of population growth does not imply that once the shock has come to an end, a baby boom occurs following the baby bust. It only means fertility regains its original level.

${ }^{11}$ The method of comparative dynamics was first introduced by Judd (1982) for a continuous-time model. It can easily be transformed to discrete time, however.
} 
As wages in both regions are equal, differences in the level of savings are completely determined by differences in time preference. In particular, this difference appears to be responsible for the long-run effects of ageing on the capital-labour ratio.

Substituting (10) into (8) gives the following capital-accumulation equation,

$$
\left(\prod_{j=0}^{t}\left(1+\pi h_{j}\right) \frac{1}{2+\rho^{D}}+\frac{1}{2+\rho^{F}}\right) w_{t}=\left(\prod_{j=0}^{t+1}\left(1+\pi h_{j}\right)+1\right) k_{t+1} .
$$

Linearising (11) around the initial steady state, the evolution of the capital-labour ratio is described by the following linear first-order difference equation,,$^{12}$

$$
\frac{\partial k_{t+1}}{\partial \pi}=-\frac{1}{2} f^{\prime \prime}(k) k\left(\frac{1}{2+\rho^{D}}+\frac{1}{2+\rho^{F}}\right) \frac{\partial k_{t}}{\partial \pi}+\frac{1}{4}\left(s^{D}-s^{F}\right) H_{t}-\frac{1}{2} k h_{t+1},
$$

with $H_{t} \equiv \sum_{j=0}^{t} h_{j}$. Whether or not ageing is anticipated, the change in the capitallabour ratio at the moment the shock occurs is unambiguously positive $\left(\frac{\partial k_{t \prime}}{\partial \pi}=\right.$ $\left.-\frac{1}{2} k h_{t^{\prime}}>0, t^{\prime}=0, t^{*}\right)$. This increase is due to the declined labour force of the world economy. The short-run effect of an anticipated shock is equal to the effect of an unexpected shock because individuals base their savings decision only on their first-period income (see equation (10)), which is not affected by future shocks. ${ }^{13}$

The term $\frac{1}{4}\left(s^{D}-s^{F}\right)$, which directly follows from equation (9), determines the (sign of the) long-run effect of a temporary demographic shock. Therefore, the longrun impact of population ageing on the capital-labour ratio depends on the difference in individual thriftiness of both regions' inhabitants. The following proposition summarises these effects.

Proposition 1 In the long run, the sign of $\frac{\partial k}{\partial \pi}$ is determined by the sign of $\left(s^{D}-s^{F}\right)$. It holds that

$$
\begin{aligned}
& \frac{\partial k}{\partial \pi}>0 \text { if } s^{D}<s^{F} \Leftrightarrow \rho^{D}>\rho^{F}, \\
& \frac{\partial k}{\partial \pi}<0 \text { if } s^{D}>s^{F} \Leftrightarrow \rho^{D}<\rho^{F}, \\
& \frac{\partial k}{\partial \pi}=0 \text { if } s^{D}=s^{F} \Leftrightarrow \rho^{D}=\rho^{F} .
\end{aligned}
$$

PRoOF In the long run, the change in the capital-labour ratio $\left(\frac{\partial k}{\partial \pi}\right)$ is determined by the fixed point of difference equation (12), which is given by $\frac{\partial k}{\partial \pi}=\frac{s^{D}-s^{F}}{4+2 f^{\prime \prime}(k) k\left(\frac{1}{2+\rho^{D}}+\frac{1}{2+\rho^{F}}\right)} H$,

\footnotetext{
${ }^{12}$ This difference equation is locally stable as $0<-\frac{1}{2} f^{\prime \prime}(k) k\left(\frac{1}{2+\rho^{D}}+\frac{1}{2+\rho^{F}}\right)<1$. For a detailed analysis of the stability properties, it is referred to Appendix B. See also Galor and Ryder (1989) and Michel and de la Croix (2000).

${ }^{13}$ Recall that due to the logarithmic felicity functions and the absence of PAYG-benefits, the current savings decision is not based on the next-period's rate of interest.
} 
where $H=\sum_{j=0}^{\infty} h_{j}<0$. Furthermore, it follows from $(10)$ that $\frac{\partial s^{i}}{\partial \rho^{i}}<0$, which completes the proof.

Proposition 1 can be interpreted as follows. If inhabitants of the domestic region are relatively impatient $\left(\rho^{D}>\rho^{F}\right)$, the level of domestic private savings will be relatively low $\left(s^{D}<s^{F}\right)$. Domestic ageing then implies that eventually, the population share of the impatient region in the world economy decreases. So the world is on average populated by relatively more patient individuals. This implies that on average, savings per individual increase, and thereby, because of perfect capital mobility, the capital-labour ratio increases. The reverse holds if the inhabitants of the domestic region are relatively patient. Ergo, a temporary demographic shock can have persistent effects on the world economy. If individuals are equally patient in both regions, average savings do not change in the long run, and the capital-labour ratio is not affected.

\section{Different Public Pension Schemes}

In the remainder we will assume that all individuals have the same pure rate of time preference, irrespective of their region of birth $\left(\rho^{D}=\rho^{F}=\rho\right)$, as we will focus on different designs of the PAYG-pension schemes. Regional governments are assumed to run the same type of pension scheme; the only difference is their generosity. We will distinguish three institutional settings with respect to the intergenerational risksharing properties. First, a Defined-Contribution $(D C)$ scheme, where the socialsecurity tax is constant and the benefit level is allowed to vary. Second, a DefinedBenefit $(D B)$ scheme, where the PAYG-tax is varied in order to keep the pension benefit at a constant level. And finally, a Fixed-Replacement (FR) scheme, where the current benefit level is a constant fraction of the current gross wage. ${ }^{14}$

\section{Defined Contribution}

If the local governments run their public pension schemes as $D C$-schemes, the socialsecurity tax is kept constant $\left(\tau_{t|\mathrm{DC}|}^{i}=\tau_{|\mathrm{DC}|}^{i}, \forall t\right)$. Apart from adjustments in private savings and the capital-labour ratio, the effects of domestic population ageing are only reflected in the benefit level, i.e.,

$$
\frac{\partial \tau_{t}^{D}[\mathrm{DC}]}{\partial \pi}=0, \quad \frac{\partial \eta_{t}^{D}[\mathrm{DC}]}{\partial \pi}=\tau^{D}{ }_{\mid \mathrm{DC}]} h_{t}, \quad \forall t
$$

Naturally, the PAYG-tax and benefit in the foreign region are not affected by the demographic shock in the other region.

\footnotetext{
${ }^{14}$ We restrict ourselves to cases where both regions have the same type of pension scheme. As is discussed in Section 4.2, this makes no significant difference to our results.
} 


\section{Defined Benefit}

If the local governments run their public pension schemes as $D B$-schemes, the level of the public pension benefit is kept constant $\left(\eta_{t}^{i}{ }_{|\mathrm{DB}|}=\eta_{[\mathrm{DB} \mid}^{i}, \forall t\right)$. Apart from adjustments in private savings and the capital-labour ratio, the effects of domestic population ageing are only reflected in the PAYG-tax, i.e.,

$$
\frac{\partial \eta_{t}^{D}[\mathrm{DB} \mid}{\partial \pi}=0, \quad \frac{\partial \tau_{t}^{D}[\mathrm{DB} \mid}{\partial \pi}=-\eta^{D}{ }_{[\mathrm{DB} \mid} h_{t}, \quad \forall t .
$$

Again, the PAYG-tax and benefit in the foreign region are not affected by the demographic shock in the other region. ${ }^{15}$

\section{Fixed Replacement Ratio}

For welfare-political reasons, government policy may be directed towards linking the public pension benefit to current gross wages. The level of the PAYG-benefit is then a constant fraction $\varphi^{i}$ of the gross wage, $\eta_{t}^{i}[\mathrm{FR}]=\varphi^{i} w_{t}$. A balanced government budget implies that the social-security tax is $\tau_{t \mid \mathrm{FR}]}^{i}=\frac{\varphi^{i} w_{t}}{1+n_{t}^{i}}$. For the domestic region, the effects of domestic population ageing on the social-security arrangements are now given by

$$
\frac{\partial \tau_{t}^{D}{ }_{[\mathrm{FR}]}}{\partial \pi}=\varphi^{D} \frac{\partial w_{t}}{\partial \pi}-\tau^{D}{ }_{[\mathrm{FR}]} h_{t}, \quad \frac{\partial \eta_{t}^{D}[\mathrm{FR}]}{\partial \pi}=\varphi^{D} \frac{\partial w_{t}}{\partial \pi}, \quad \forall t
$$

where $\tau_{[\mathrm{FR}]}^{D}=\eta^{D}{ }_{[\mathrm{FR}]}=\varphi^{D} w$ and $\frac{\partial w_{t}}{\partial \pi}=f^{\prime \prime}(k) k \frac{\partial k_{t}}{\partial \pi}$. For the foreign region, these effects are

$$
\frac{\partial \tau_{t}^{F}[\mathrm{FR} \mid}{\partial \pi}=\frac{\partial \eta_{t}^{F}[\mathrm{FR}]}{\partial \pi}=\varphi^{F} \frac{\partial w_{t}}{\partial \pi}, \quad \forall t,
$$

with $\tau_{[\mathrm{FR}]}^{F_{1}}=\eta^{F}{ }_{[\mathrm{FR}]}=\varphi^{F} w$. Contrary to the settings with $D C$ - and $D B$-schemes, the domestic social-security arrangements are not only directly affected by population ageing, but also indirectly through changes in the capital-labour ratio that influence the gross wage. As capital is perfectly mobile and therefore the (change in the) gross wage is the same for both regions, domestic ageing now also affects the foreign public pension arrangements.

In the following, we will assume that, irrespective of the institutional design of the public pension schemes, the initial level of the PAYG-tax is the same, i.e., $\tau^{i}{ }_{[\mathrm{DC}]}=$ $\tau_{|\mathrm{DB}|}^{i}=\tau_{|\mathrm{FR}|}^{i}=\tau^{i}, i=D, F$. This implies that the initial steady-state values of all

\footnotetext{
${ }^{15}$ As democratic governments exhibit a tendency to orientate themselves more towards the interests of larger voting groups, one could also assume that the generosity of the social-security scheme depends on the relative number of older and younger voters. This relative number is reflected in the rate of population growth. Therefore, the PAYG-tax could be a function of this growth rate, i.e., $\tau_{t}^{i}=\tau^{i}\left(n_{t}^{i}\right)$. Ageing then has an upward pressure on the PAYG-tax, $\frac{\partial \tau_{t}^{D}}{\partial \pi}=\tau^{\prime} h_{t}$, where $\tau^{\prime}<0$ denotes the marginal political influence of an individual young voter, as she strives for a low PAYG-tax. These simple politics are captured by our $D B$-setting if one assumes that $\tau^{\prime}=-\eta^{D}[\mathrm{DB}]$.
} 
other variables are also the same, irrespective of the specific form of intergenerational redistribution. Therefore, to avoid notational complexity, the subscript referring to the specific pension scheme is omitted in the initial steady state.

\subsection{The Effects of Population Ageing}

As mentioned before, the consequences of a (temporary) decline in the domestic rate of population growth can be traced by linearising equation (8), where $s_{t}^{i}$ is given by (6). For the different institutional settings, $X=D C, D B, F R$, this linearisation eventuates in the following first-order difference equation,

$$
\frac{\partial k_{t+1}[\mathrm{x}]}{\partial \pi}=\alpha_{[\mathrm{X}]} \frac{\partial k_{t}[\mathrm{x}]}{\partial \pi}+\beta_{[\mathrm{x}]} h_{t}+\gamma_{[\mathrm{x}]} h_{t+1}+\delta_{[\mathrm{x}]}\left(\tau^{F}-\tau^{D}\right) H_{t}
$$

Appendix B specifies the parameters of (16) for the different pension schemes. For all settings, difference equation (16) is locally stable as $0<\alpha_{\mid \mathrm{x}]}<1, X=D C, D B$, $F R$. Besides local stability, the following assumption will hold.

Assumption II For any institutional design of the regional pension schemes, it is assumed that

$$
\left|\frac{\partial s^{i}{ }_{t \mid \mathrm{x}]}}{\partial k_{t \mid \mathrm{x}]}}\right|>\left|\frac{\partial s^{i}{ }_{t \mid \mathrm{x}]}}{\partial k_{t+1 \mid \mathrm{x}]}}\right|, \quad i=D, F, \quad \forall t .
$$

So, together with the fact that $\frac{\partial s^{i} t|\mathrm{X}|}{\left.\partial k_{t} \mid \mathrm{X}\right]}>0$ and $\frac{\left.\partial s^{i} t \mid \mathrm{X}\right]}{\partial k_{t+1}[\mathrm{X}]} \leq 0$, it holds that $\frac{\partial s^{i} t|\mathrm{X}|}{\left.\partial w_{t} \mid \mathrm{X}\right]}>$ $\frac{\left.\partial s^{i} \mid \mathrm{X}\right]}{\partial r_{t+1}[\mathrm{X}]} \geq 0$. This seems plausible, since for our specification of the utility function, a change in the rate of interest only affects the net present value of the PAYG-benefit. ${ }^{16}$ Moreover, the assumption implies that in the long run, there is a positive relation between private savings and the capital-labour ratio $\left(\frac{\partial s^{i}|\mathrm{X}|}{\partial k|\mathrm{X}|}>0\right)$. As can be seen from Appendix B, Assumption II induces a positive upper bound for the (initial) generosity of the local social-security arrangements.

First, we analyse the long-run effects of a temporary shock to the rate of population growth of the domestic inhabitants. Second, we describe the short-run dynamics of such a demographic shock. In particular, we focus on the effects of unexpected ageing versus anticipated ageing.

\section{The long-run effects}

The following proposition describes the long-run effects of domestic ageing on the capital-labour ratio.

\footnotetext{
${ }^{16} \frac{\partial s^{i}{ }_{t}|\mathrm{X}|}{\partial r_{t+1}|\mathrm{X}|}=0$ whenever $\tau_{t+1}^{i}=0$ due to the logarithmic felicity functions. However, we restrict ourselves to situations with a positive social security tax over time.
} 
Proposition 2 In the long run, the sign of $\frac{\partial k[X]}{\partial \pi}$ is determined by the sign of $\left(\tau^{F}-\right.$ $\left.\tau^{D}\right)$.

(i) For $X=D C, D B, F R$ it holds that

$$
\begin{array}{llc}
\frac{\partial k_{[\mathrm{X}]}}{\partial \pi}>0 & \text { if } & \tau^{F}<\tau^{D} \Leftrightarrow s^{D}<s^{F} \\
\frac{\partial k_{[\mathrm{X}]}}{\partial \pi}<0 & \text { if } & \tau^{F}>\tau^{D} \Leftrightarrow s^{D}>s^{F} \\
\frac{\partial k_{[\mathrm{X}]}}{\partial \pi}=0 & \text { if } & \tau^{F}=\tau^{D} \Leftrightarrow s^{D}=s^{F} .
\end{array}
$$

(ii) Furthermore, it holds that

$$
\left|\frac{\partial k_{[\mathrm{DC}]}}{\partial \pi}\right|=\left|\frac{\partial k_{[\mathrm{DB}]}}{\partial \pi}\right| \geq\left|\frac{\partial k_{[\mathrm{FR}]}}{\partial \pi}\right| .
$$

PROOF (i) In the long run, the change in the capital-labour ratio $\left(\frac{\partial k|\mathrm{x}|}{\partial \pi}\right)$ is determined by the fixed point of difference equation (16), which is given by $\frac{\partial k|\mathrm{x}|}{\partial \pi}=$ $\frac{\delta|\mathrm{X}|}{1-\alpha|\mathrm{X}|}\left(\tau^{F}-\tau^{D}\right) H$. As $\delta_{|\mathrm{x}|}>0$ and $\alpha_{|\mathrm{x}|} \in(0,1)$, the relation between $\frac{\partial k|\mathrm{x}|}{\partial \pi}$ and $\left(\tau^{F}-\tau^{D}\right)$ immediately follows. The inverse relation between savings and the generosity of the social-security scheme follows from (4), (6), and the assumption of dynamic efficiency. (ii) Relation (18) follows from $\frac{\delta[\mathrm{DC}]}{1-\alpha[\mathrm{DC}]}=\frac{\delta[\mathrm{DB}]}{1-\alpha[\mathrm{DB}]}>\frac{\delta[\mathrm{FR}]}{1-\alpha|\mathrm{FR}|}$. The equality holds for $\tau^{F}=\tau^{D}$, because then $\frac{\partial k|\mathrm{x}|}{\partial \pi}=0$, which completes the proof.

Notice that the sign of the long-run change in the capital-labour ratio is independent of the institutional design of the regional pension schemes; it only depends on the relative generosity of the local social-security arrangements. The first part of Proposition 2 can be interpreted as follows. If the government of the domestic economy runs a relatively generous public pension scheme $\left(\tau^{D}>\tau^{F}\right)$, the level of domestic private savings will be relatively low $\left(s^{D}<s^{F}\right)$. Domestic ageing then implies that eventually, the population share of the domestic region in the world economy decreases. So individual savings increase on average, and thereby, because of perfect capital mobility, the capital-labour ratio. This implies a reduction of the interest rate and an increase of the (gross) wage. A lower interest rate causes savings to decline, while a higher wage stimulates savings. ${ }^{17}$ As by assumption, the latter effect dominates the former, savings eventually increase. The second part of Proposition 2 states that the change in the capital-labour ratio is smaller if the regional governments operate a $F R$-scheme. Suppose $\tau^{D}>\tau^{F}$; the capital-labour ratio then increases, $\frac{\partial k \mid \mathrm{FR}]}{\partial \pi}>0$. This causes the wage to increase in both regions. Because pension benefits are a

\footnotetext{
${ }^{17}$ For $D C$ - and $D B$-schemes, the relation between the wage and individual savings is unambiguously positive, both in the short run and in the long run. However, in case of a $F R$-scheme, this relation is only positive (in the long run) if $\varphi^{i}<\frac{1+r}{2+r+p}$.
} 
constant fraction of the wage in this setting, both social-security taxes and benefits will be higher, which in turn has a negative impact on private savings. Therefore, the increase in the capital-labour ratio will eventually be lower than in a setting with a $D C$ - or a $D B$-scheme. In the latter two settings, the capital-labour ratio changes to the same extent because in the long run, the size of intergenerational redistribution is not affected by a temporary demographic shock (see equations (13) and (14)).

If savings increase, then there is a shift from the inefficient unfunded social-security arrangements to a more efficient funded pension system. Together with the increased wage this will have a positive effect on overall long-run welfare, irrespective of the institutional setting. This effect is smaller in case of a $F R$-scheme because, as mentioned above, the increased wages also imply an extension of the inefficient PAYG-scheme (in both regions).

The reverse holds if $\tau^{D}<\tau^{F}$. A FR-scheme then implies that the decrease in overall long-run welfare will be smaller relative to the other two settings. This is due to the decreased capital-labour ratio, implying a lower wage and thereby smaller (inefficient) unfunded social-security outlays. So a $F R$-scheme curbs the long-run effects of demographic changes.

Finally, if $\tau^{F}=\tau^{D}$, a temporary demographic shock will not affect the average long-run level of private savings and therefore the capital-labour ratio will remain unaltered; lifetime utility of inhabitants of both regions will eventually not be affected either.

\section{The short-run dynamics}

In the short run, we distinguish between unexpected and anticipated ageing. We first analyse the effects of an unexpected asymmetric demographic shock, i.e., an unanticipated decline in the domestic rate of population growth.

unexpected ageing

If at time $t=0$ a once-only negative shock to the domestic rate of population growth unexpectedly occurs $\left(h_{0}<0\right)$, the capital-labour ratio will increase, irrespective of the institutional design and the (relative) generosity of the regional social-security arrangements, that is,

$$
\frac{\partial k_{0 \mid \mathrm{x}]}}{\partial \pi}=-\frac{k}{2} h_{\mathbf{0}}>0, \quad X=D C, D B, F R .
$$

This capital thickening is due to the labour force being smaller than expected, implying a larger capital stock per worker, both in the domestic and the foreign region. This leads to a decrease in the rate of interest and an increase in the wage. Besides the capital-thickening effect, the inhabitants of the domestic region are also confronted with an increase in the dependency ratio, that is, an eroding tax base. This eroding tax base harms the domestic elderly alive at the time the shock occurs 
if a $D C$-scheme is in place. In case of a $D B$-scheme, the current domestic young have to pay an additional amount of taxes to keep the PAYG-benefit in the domestic region at its current level. When the benefit is linked to their (increased) gross wage (FR-scheme), the current young inhabitants of both regions are confronted with a higher PAYG-tax. Since the dependency ratio in the domestic economy increases when the shock occurs, the additional amount the current domestic young have to pay under a $F R$-scheme will exceed the additional payments of the current foreign young. Note that, if a FR-scheme is in place, the PAYG-benefit of the elderly alive at the moment ageing occurs increases, irrespective of their region of birth. They may even benefit in terms of lifetime utility from the demographic change if the increased benefits outweigh the decline in the returns on their savings.

Private savings of the young at time $t=0$ unambiguously increase in case of a $D C$-scheme (due to Assumption II). With a $D B$-scheme, average savings increase less relative to the increase under a $D C$-scheme because the domestic young are now confronted with a higher PAYG-tax and next-period pension benefits equal those under a $D C$-scheme. ${ }^{18}$ Under a $F R$-scheme, the increase in average savings is even smaller than with a $D B$-scheme due to, on the one hand, the higher taxes they pay when young, and, on the other hand, the increased benefits they receive when old as a result of the fact that benefits are linked to gross wages. Because of the specific nature of the demographic shock (a once-only decrease in $n^{D}$ at time $t=0$ ), lifetime utility of both the domestic and foreign young individuals alive at the moment ageing occurs initially increases the least under a $F R$-scheme, as in this case the inefficient PAYGscheme is extended in the short run. ${ }^{19}$ Lifetime utility of the domestic young born at time $t=0$ increases relatively more under a $D C$-scheme than under a $D B$-scheme if the increased tax payments under the latter regime outweigh the lower interest rate at time $t=1$ under the former regime. Lifetime utility of the foreign young born at time $t=0$ unambiguously increases the most in case of a $D B$-scheme because the interest rate at time $t=1$ is higher for a $D B$-scheme than for a $D C$-scheme. This higher interest rate is a result of a smaller increase in average savings as under the former regime the increase in domestic savings is confined by increased tax payments.

Notice that the results described above do not depend on the relative generosity of the regional social-security arrangements; the relative generosity merely has quantitative implications. Figure 1 to Figure 3 display the evolution over time of the capital-labour ratio (Figure 1) and the lifetime utility of the inhabitants of both regions (Figures 2 and 3 ), for the case where $\tau^{D}<\tau^{F} .{ }^{20}$ If $\tau^{D} \geq \tau^{F}$, the figures would be

\footnotetext{
${ }^{18}$ The net present value of the next-period benefit is even higher in case of a $D C$-scheme than under a $D B$-scheme, as the smaller increase in savings in the latter case implies a higher next-period interest rate.

${ }^{19}$ Under a $D B$ - or $F R$-scheme, the net wages of the domestic generation born at the time of the shock may decrease and thereby their private savings and even lifetime utility. The exact condition for this decrease in net wages is given in Appendix B.

${ }^{20}$ The figures are based on the following Cobb-Douglas production technology, $f(k)=\sqrt{k}$. Furthermore, $\rho=0$ and $\tau^{D}=\frac{1}{2} \tau^{F}=0.104 w$. This results in $k=0.04$ and $r=2.5$.
} 
similarly shaped, since the parameters of difference equation (16) do not change sign.

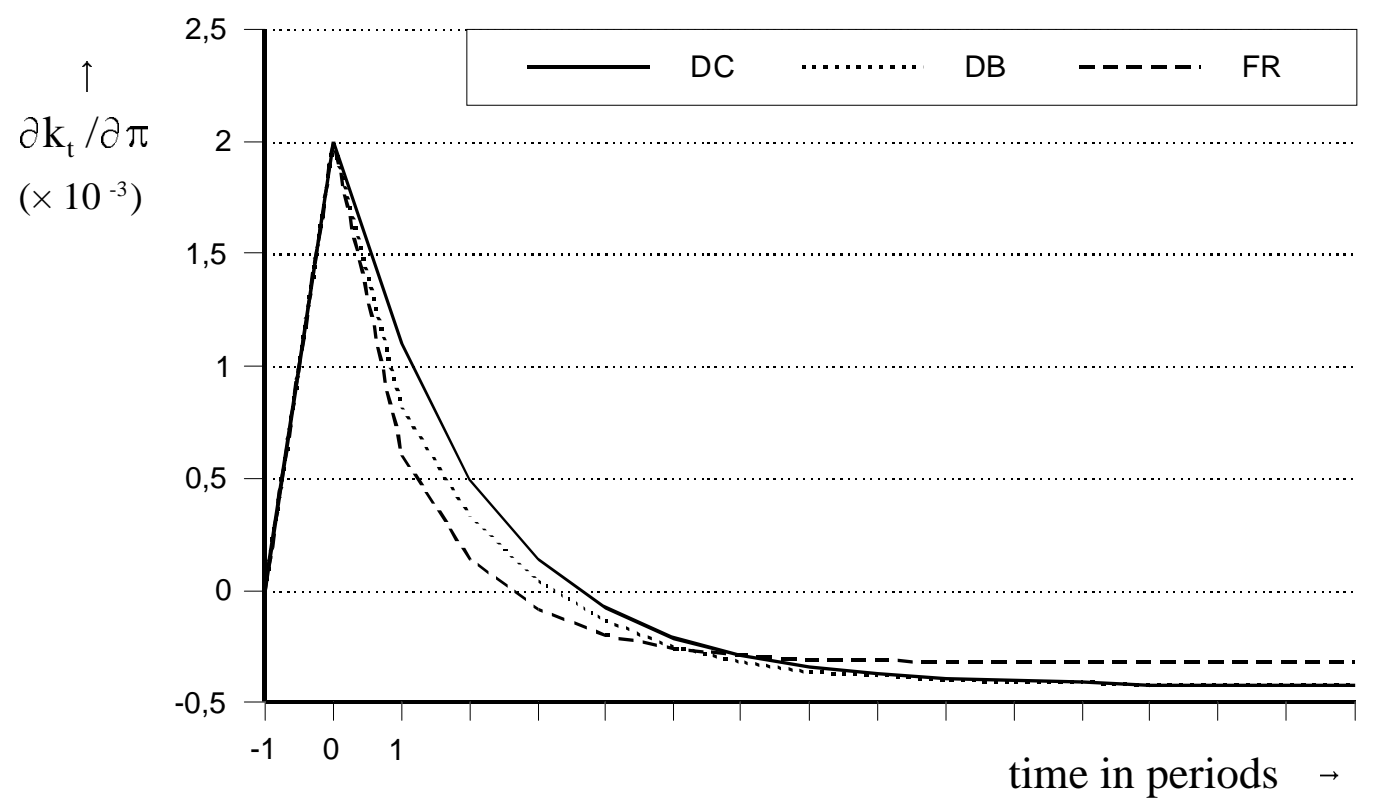

Figure 1 Evolution of the Capital-Labour Ratio over Time

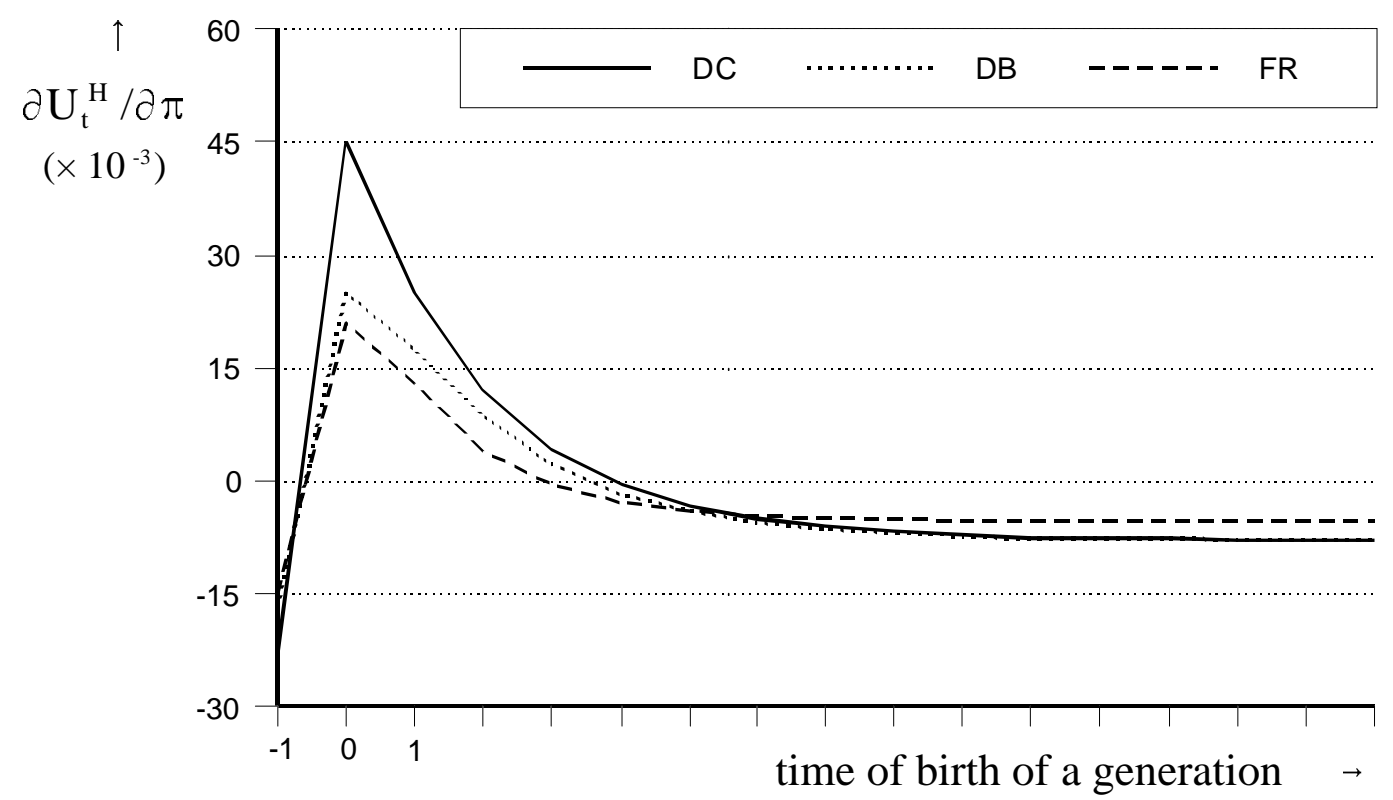

Figure 2 Evolution of Lifetime Utility of Domestic Agents 


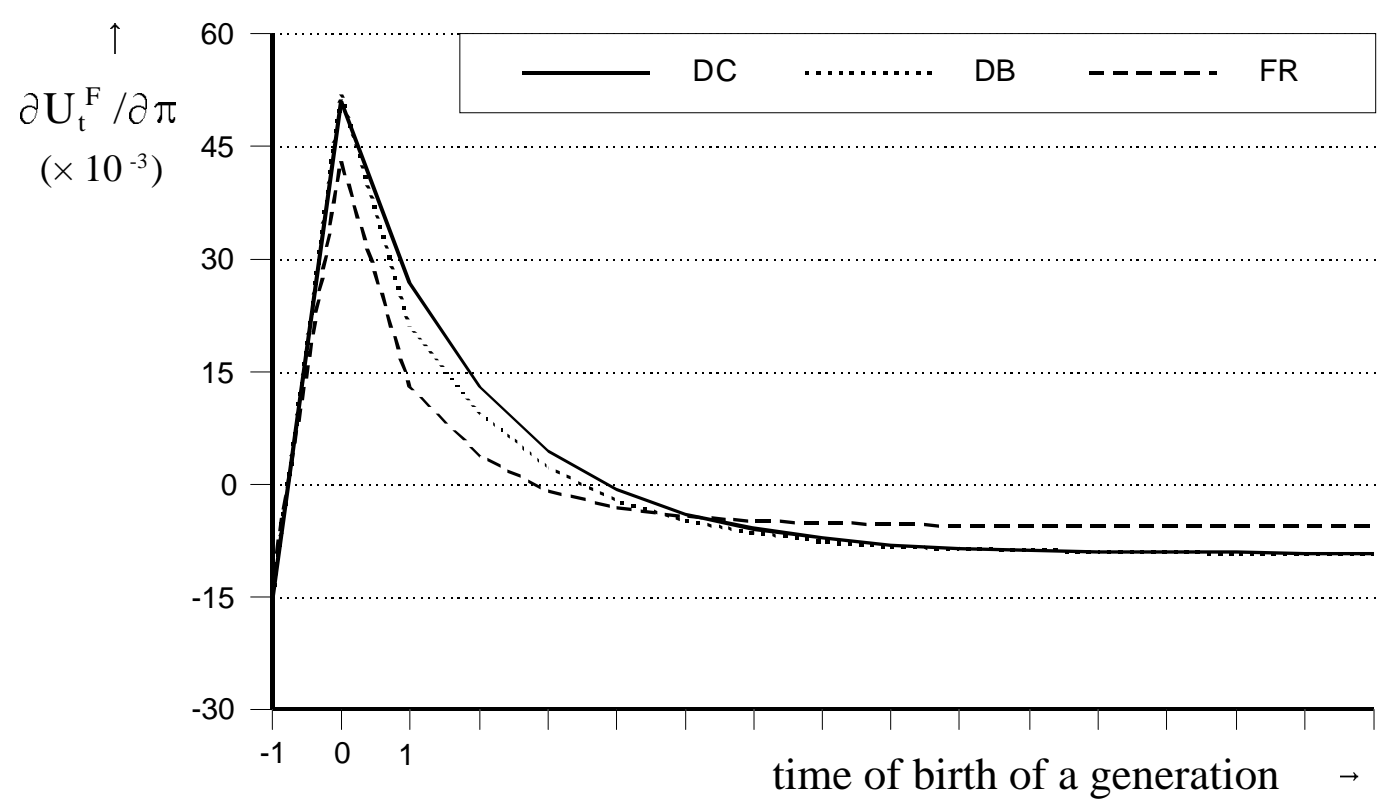

Figure 3 Evolution of Lifetime Utility of Foreign Agents

Next we describe the economic effects of an anticipated demographic shock.

\section{anticipated ageing}

If it becomes publicly known at time $t=0$ that a once-only negative demographic shock to the domestic rate of population growth will occur at time $t=t^{*}>0$ $\left(h_{t^{*}}<0\right.$ ), the generations born (in either region) at time $t=0$ through $t=t^{*}-2$ will not adapt their behaviour because this shock does not affect any economic variable during the time interval $\left[0, t^{*}-2\right]$, so $\frac{\partial k_{t}|\mathrm{X}|}{\partial \pi}=0, t=0,1, \ldots, t^{*}-1$. In particular, note that $\frac{\left.\partial k_{t^{*}-1} \mid \mathrm{x}\right]}{\partial \pi}=0$, as a change in the capital labour ratio at time $t=t^{*}-1$ can only be brought about by either a change in the level of savings at time $t=t^{*}-2$ in any region $\left(\frac{\partial s_{t^{*}-2}^{i}[\mathrm{x}]}{\partial \pi}\right)$, or a change in the domestic rate of population growth at time $t=t^{*}-1\left(\frac{\partial n_{t^{*}-1}^{D}}{\partial \pi}=h_{t^{*}-1}\right)$ (see the capital-accumulation equation $(8)$ ); neither of these variables is affected by the shock at time $t=t^{*} \cdot{ }^{21}$

The generation born at time $t=t^{*}-1$ is the first to adapt its behaviour to the next-period shock. This adaptive behaviour is due to the next-period rate of interest $\left(r_{t^{*}}\right)$ and their pension benefit $\left(\eta_{t^{*}|\mathrm{x}|}^{i}\right)$ possibly being affected by the demographic shock. Ageing implies - ceteris paribus - capital thickening, i.e., an increase in the

\footnotetext{
${ }^{21}$ Allowing for endogenous labour supply does change the results in this respect, as is described in Section 4.2
} 
capital-labour ratio. The increased capital-labour ratio results in a decrease of the interest rate which negatively affects savings as it holds that $\frac{\partial s^{i} t|\mathrm{X}|}{\partial r_{t+1}|\mathrm{X}|}>0$. Furthermore, a higher capital-labour ratio also leads to higher wages for the young workers at time $t=t^{*}$. In case of a $F R$-scheme, higher wages imply higher benefits. Besides these effects caused by capital thickening, the domestic region also incurs an increase in the dependency ratio at the moment of the shock. This erosion of the tax base will result in a higher PAYG-tax that the domestic young born at time $t=t^{*}$ have to pay in order to keep the benefit level constant ( $D B$-scheme), or in addition to the already higher taxes due to capital thickening ( $F R$-scheme). In case of a $D C$-scheme, taxes are constant by definition and therefore an increase in the domestic dependency ratio at time $t=t^{*}$ will result in lower pension benefits for the elderly born at time $t=t^{*}-1$. The short-run effects of an anticipated demographic shock on the capitallabour ratio for the different public pension schemes are summarised by the following proposition.

Proposition 3 Given that the ageing of the domestic population at time $t=t^{*}$ is anticipated, it holds that

(i) at the time the shock occurs, the capital-labour ratio changes the most if a DCscheme is in place and the least if a FR-scheme is in place,

$$
\frac{\partial k_{\left.t^{\star} \mid \mathrm{DC}\right]}}{\partial \pi}>\frac{\partial k_{t^{\star}[\mathrm{DB}]}}{\partial \pi}>\frac{\partial k_{\left.t^{\star} \mid \mathrm{FR}\right]}}{\partial \pi}>0
$$

(ii) for $h_{0}=h_{t^{*}}<0$, the initial marginal change in the capital-labour ratio due to an unexpected shock $\left[\frac{\partial k_{0}|\mathrm{X}|}{\partial \pi}\right]_{\text {unexpected }}$ and the marginal change due to an anticipated shock $\left[\frac{\partial k_{t^{*}|\mathrm{x}|}}{\partial \pi}\right]_{\text {anticipated }}$ are related as follows,

$$
\begin{gathered}
{\left[\frac{\partial k_{\mathbf{0}[\mathrm{Y}]}}{\partial \pi}\right]_{\text {unexpected }}>\left[\frac{\partial k_{\left.t^{\star} \mid \mathrm{Y}\right]}}{\partial \pi}\right]_{\text {anticipated }}, \quad Y=D B, F R,} \\
{\left[\frac{\partial k_{\mathbf{0}[\mathrm{DC}]}}{\partial \pi}\right]_{\text {unexpected }} \gtreqless\left[\frac{\partial k_{\left.t^{*} \mid \mathrm{DC}\right]}}{\partial \pi}\right]_{\text {anticipated }}, \text { if } \frac{\tau^{D}}{\tau^{F}} \lesseqgtr-\frac{k f^{\prime \prime}(k)}{2(1+r)+k f^{\prime \prime}(k)} .}
\end{gathered}
$$

Proof (i) If ageing is anticipated, the initial increase in the capital-labour ratio is given by $\left[\frac{\left.\partial k_{t^{*}|\mathrm{X}|}\right]}{\partial \pi}\right]_{\text {anticipated }}=\gamma_{[\mathrm{X} \mid} h_{t^{*}}$ (see equation $\left.(16)\right)$. As $\gamma_{\mid \mathrm{DC}]}<\gamma_{[\mathrm{DB}]}<\gamma_{\mid \mathrm{FR}]}<0,(20)$ immediately follows. (ii) Relation (21) follows from $-\frac{k}{2}<\gamma_{\mid \mathrm{Y}]}<0, Y=D B, F R$. Relation (22) directly follows from $-\frac{k}{2} \lesseqgtr \gamma_{\mid \mathrm{DC}]}$, that boils down to $\frac{\tau^{D}}{\tau^{F}} \lesseqgtr-\frac{k f^{\prime \prime}(k)}{2(1+r)+k f^{\prime \prime}(k)}$, which completes the proof.

The first part of Proposition 3 can be interpreted as follows. Due to capital thickening, the capital-labour ratio increases, but as this increase is anticipated by the generation 
born just before the shock occurs, this increase is confined by a decrease in the level of private savings in period $t=t^{*}-1$. In case of a $D C$-scheme, this decrease in savings in the domestic region is smaller relative to the decrease in domestic savings with a $D B$-scheme, since in the former case, the lower pension benefits due to an increased dependency ratio are (partly) compensated (this can even result in an increase of domestic savings as we will show later on). So, average savings decline more in a setting with a $D B$-scheme compared to a setting with a $D C$-scheme. Given a $F R$ scheme, the anticipative decrease in average savings is even larger because (contrary to a $D B$-scheme) pension benefits then increase due to the linking to the wage.

The second part of Proposition 3 states that for a $D B$ - or a FR-scheme, the increase in the capital-labour ratio is larger if the shock is not expected. This is because of the anticipative decrease in average savings. In a setting with a $D C$ scheme, the dependency-ratio effect can dominate the capital-thickening effect, and thus domestic savings at time $t=t^{*}-1$ may even increase. In the foreign region, savings are only affected by capital thickening and therefore decrease. If the domestic increase in savings dominates the foreign decrease, average private savings go up. So the increase in the capital-labour ratio in case of anticipated ageing may be larger than the increase as a result of an unexpected demographic shock. In case of a Cobb-Douglas production function, $f\left(k_{t}\right)=k_{t}^{a}, a \in(0,1)$, the condition given in (22) reduces to $\frac{\tau^{D}}{\tau^{F}} \lesseqgtr \frac{(1-a) a k^{a-1}}{2+(1+a) a k^{a-1}}$. So for this specification it holds that $\left[\frac{\left.\partial k_{t^{*}|\mathrm{DC}|}\right]}{\partial \pi}\right]_{\text {anticipated }}>$ $\left[\frac{\partial k_{0}|\mathrm{DC}|}{\partial \pi}\right]_{\text {unexpected }}$ if $\tau^{D}>\tau^{F}$.

Again, the results described above do not depend on the relative size of the regional public pension schemes, except for the relation described in (22). Figure 4 to Figure 6 display the evolution over time of the capital-labour ratio (Figure 4) and the lifetime utility of the inhabitants of both regions (Figures 5 and 6 ) for an anticipated shock that occurs at time $t=1,\left(t^{*}=1\right)$, for the case where $\tau^{D}<\tau^{F} \cdot{ }^{22}$

\footnotetext{
${ }^{22}$ Figures 4 to 6 are based on the same parametrisation as Figures 1 to 3, i.e., a Cobb-Douglas production technology, $f(k)=\sqrt{k}, \rho=0$ and $\tau^{D}=\frac{1}{2} \tau^{F}=0.104 \mathrm{w}$.
} 


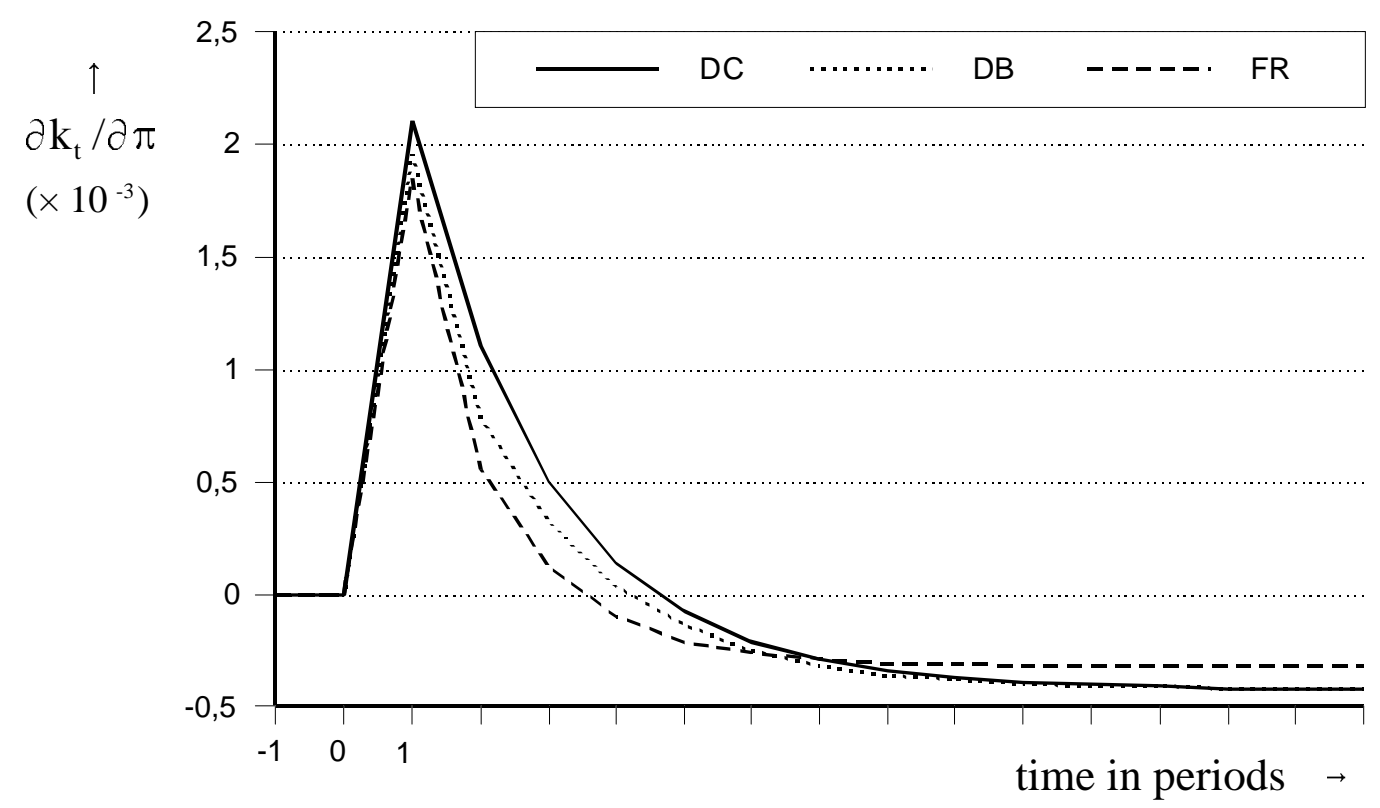

Figure 4 Evolution of the Capital-Labour Ratio over Time

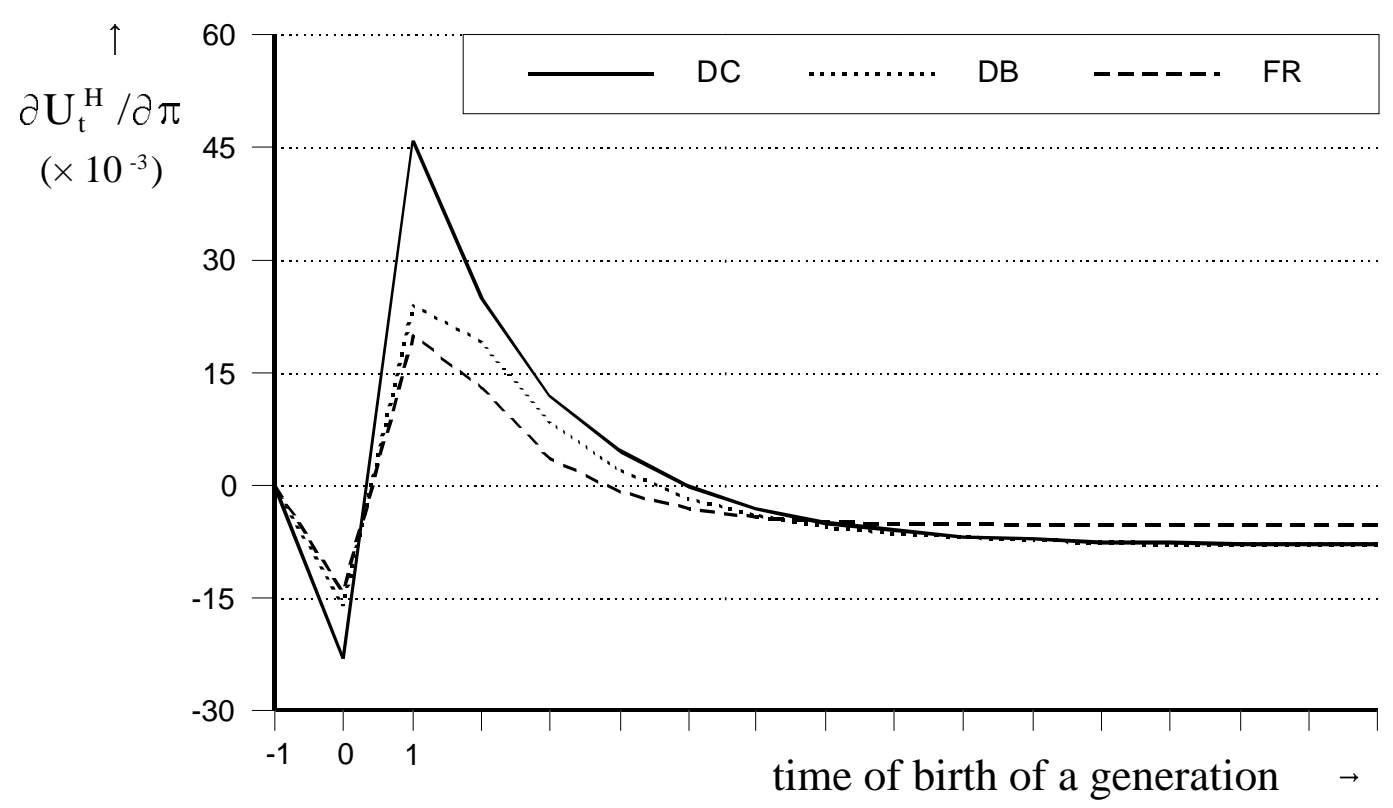

Figure 5 Evolution of Lifetime Utility of Domestic Agents 


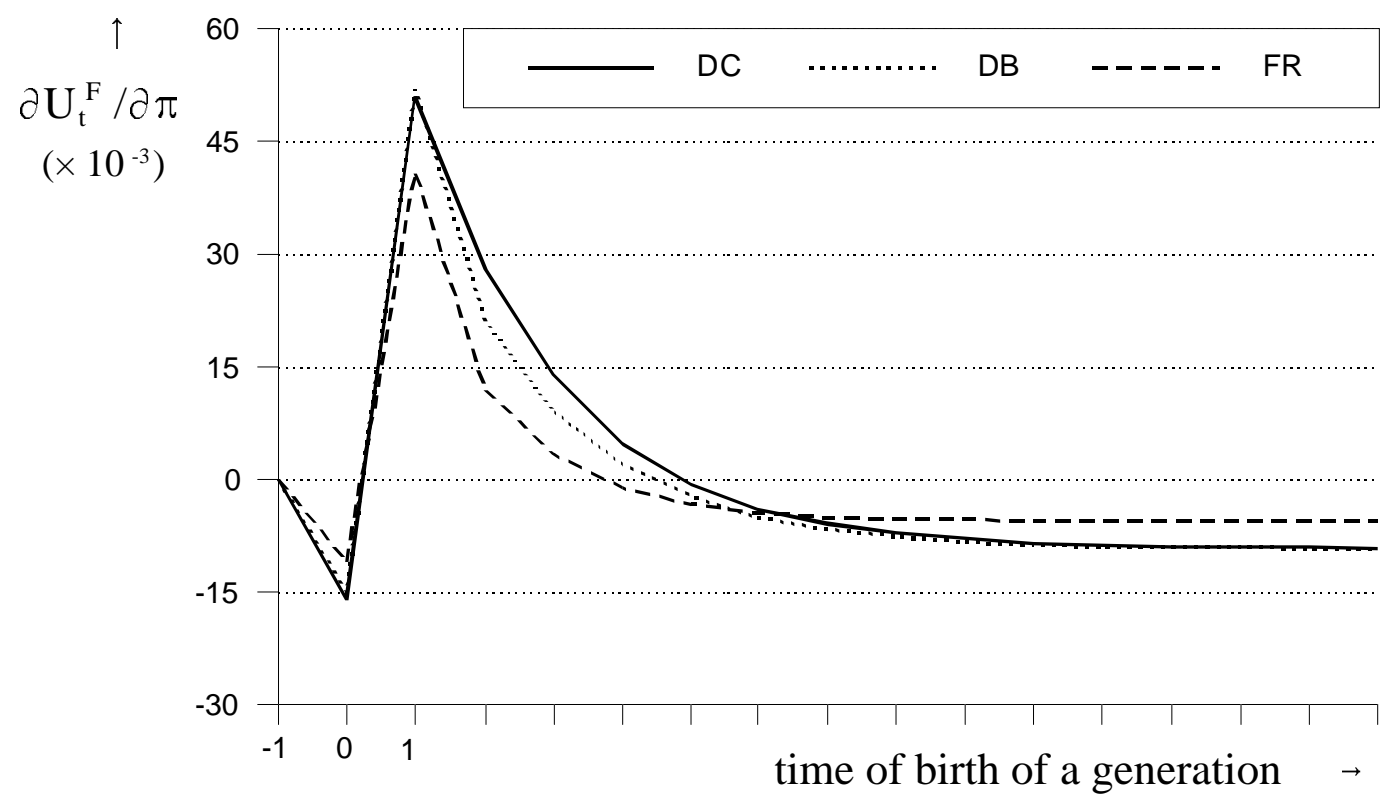

Figure 6 Evolution of Lifetime Utility of Foreign Agents

\subsection{Modifications}

This section is devoted to relaxing some of our assumptions and how this would change our main results. We first introduce short-term capital rigidity. Second, we allow for elastic supply of labour. After that, we analyse the implications of international labour mobility. The next modification is a proportional social-security tax instead of lump-sum taxation. Finally, we discuss international differences in the design of regional pension schemes.

\section{Capital rigidities}

Relaxing Assumption I allows for the existence of short-term capital rigidities ${ }^{23}$ and therefore, capital cannot be instantaneously moved to the region yielding the highest return. This amounts to regarding capital as machinery and factories, that are immobile in the short run. If a region is unexpectedly hit by a (demographic) shock, the inhabitants will then not be able to adjust their stock of capital at once. Consequently, the regions will temporarily face different rates of interest, and thereby different capital-labour ratios. How short-term capital immobility influences our re-

\footnotetext{
${ }^{23}$ We are aware of the fact that our modelling of imperfect capital mobilty is somewhat unconventional but suffices our purposes. A more standard way would be to follow the adjustment-cost approach by Hayashi (1982), but this is beyond the scope of our analysis.
} 
sults with respect to differences in individual thriftiness and different types of public pension schemes, is discussed below.

\section{Different pure rates of time preference}

If the capital stock is not mobile in the short run, an unexpected shock to the domestic rate of population growth at time $t=0\left(h_{\mathbf{0}}<0\right)$ implies the following initial shifts in the capital-labour ratios of both regions,

$$
\frac{\partial k_{0}^{D}}{\partial \pi}=-k h_{\mathbf{0}}>0, \quad \frac{\partial k_{0}^{F}}{\partial \pi}=0 .
$$

So, wages and interest rates initially differ among the two regions. Due to the shortterm capital rigidity, the spillover effects of domestic ageing on the foreign region are reduced. The older generation residing in the foreign region at time $t=0$ is not at all confronted with the effects of the ageing of the population in the domestic region. The younger generation born at the beginning of period 0 in the foreign region is only confronted with a different capital-labour ratio in the next period, when they are old. Since the change in the next-period capital-labour is only reflected in the interest rate and because the next-period interest rate does not affect the current savings decision (due to our specification of the utility function and the absence of public pensions), there will initially be no spillover effects at all. Consequently, the burden and blessings of a lower domestic rate of population growth are completely felt by the inhabitants of the region that is hit by the shock. The workers are now blessed by an additional increase in their wage, while the retirees have to bear the burden of a larger decrease in the domestic rate of interest, compared to the case where short-term capital rigidities are absent. It immediately follows from (12) that the next-period change in the capital-labour ratio (which is the same for both regions) is larger (smaller) relative to the case with an instantaneous adjustment of the capitallabour ratio if the domestic region is a net lender (borrower),

$$
\left[\frac{\partial k_{1}}{\partial \pi}\right]_{\text {rigidities }} \gtreqless\left[\frac{\partial k_{1}}{\partial \pi}\right]_{\text {no rigidities }} \text { if } \quad \rho^{D} \lesseqgtr \rho^{F} .
$$

This difference is due to patient (impatient) individuals saving relatively more (less) of the additional wage income. From period 1 on, the evolution of the capital-labour ratio over time is similar to the evolution described in Section 3 and is given by difference equation (12).

\section{Different types of pension schemes}

If the capital stock is immobile in the short run, unexpected ageing of the domestic population at time $t=0$ implies a similar asymmetric initial shift in the capitallabour ratio as in case of differences in individual thriftiness (see (23)). So, wages 
and interest rates initially also differ among the regions. Again, the spillover effects are reduced. The older generation residing in the foreign region at time $t=0$ is not at all confronted with the effects of the ageing of the population in the domestic region. The younger generation born at the beginning of period 0 in the foreign region is only confronted with a different rate of interest in the next period, and a change in the pension benefits they receive when old (if the foreign government runs a $F R$-scheme). As the change in the interest rate influences the net present value of the pension benefits, the current savings decision is affected, irrespective of the type of pension scheme in the foreign region. So the burden and blessings of the decline in the domestic rate of population growth are shifted abroad to a lesser extent, relative to the case where capital rigidities are absent. The domestic workers are now blessed by an additional increase in their wage, while the pensioners suffer from an additional decrease in the domestic rate of interest. It immediately follows from (16) that the next-period change in the capital-labour ratio (which is the same for both regions) is equal to the case with an instantaneous adjustment of the capital-labour ratio if the local governments both run a $D C$ - or a $D B$-scheme, irrespective of its relative generosity. In case of a $F R$-scheme, however, the change in the capital-labour ratio at time $t=1$ will be larger (smaller) if the size of the domestic social-security arrangements are relatively small (large), i.e.,

$$
\begin{aligned}
{\left[\frac{\left.\partial k_{1} \mid \mathrm{Y}\right]}{\partial \pi}\right]_{\text {rigidities }} } & =\left[\frac{\partial k_{1}[\mathrm{Y}]}{\partial \pi}\right]_{\text {no rigidities }} & Y=D C, D B, \\
{\left[\frac{\partial k_{1 \mid \mathrm{FR}]}}{\partial \pi}\right]_{\text {rigidities }} } & \gtreqless\left[\frac{\partial k_{1 \mid \mathrm{FR}]}}{\partial \pi}\right]_{\text {no rigidities }} & \text { if } \quad \varphi^{D} \lesseqgtr \varphi^{F} .
\end{aligned}
$$

Equation (25.a) immediately follows from the fact that the positive impact of initial capital thickening on the wage is not affected by the (size of the) social-security arrangements. In case of a $F R$-scheme (equation (25.b)), the positive impact of capital thickening on the net wage is confined by the fact that capital thickening also implies an increase in the PAYG-tax as benefits are linked to gross wages. From period 1 on the evolution over time of the capital-labour ratio is similar to the evolution described in Section 4.1 and is given by difference equation (16).

\section{Elastic labour supply}

If we incorporate elastic labour supply into our framework, individuals have an additional instrument to react to a demographic shock. Besides adapting their private savings, they can also adjust the allocation of their time endowment over labour and leisure. If we assume that both material consumption and leisure are normal goods, a decrease (increase) in material consumption possibilities is accompanied by a decrease (increase) in leisure time, implying an increase (decrease) in the amount of labour supplied. By varying their labour supply, individuals affect the tax base. If taxes 
and benefits are to some extent related to this tax base, the size of intergenerational redistribution is thereby affected too (for example, if taxes are levied proportionally as discussed below).

In particular, elastic supply of labour is of significance if ageing is expected. Suppose that it becomes publicly known at time $t=0$ that a negative demographic shock to the domestic rate of population growth will occur at time $t=t^{*}>0$. The generation born at time $t=t^{*}-1$ will adapt its behaviour because this shock changes - ceteris paribus - the interest rate and the pension benefits in period $t^{*}$. The generation born just before the shock will anticipate by changing their private savings and the amount of time spent on labour activities. A change in the supply of labour in period $t^{*}-1$ affects the tax base at that time and thereby (possibly) the pension benefits of the generation born at time $t=t^{*}-2$. This generation will react to a change in their pension benefits by altering their savings and supply of labour. So, the tax base at time $t=t^{*}-2$ will be affected implying anticipative behaviour of the generation born at time $t=t^{*}-3$. As this process of anticipative behaviour of generations continues back in time, the generation of youngsters alive at the moment the future shock becomes public will also anticipate. Therefore, incorporating elastic labour supply implies that demographic shocks can have consequences for economic behaviour as soon as the shock becomes publicly known.

\section{Labour mobility}

In the absence of perfect international capital mobility, allowing for international mobility of labour will affect our results as follows. We will distinguish between permanent and temporary migration regimes, which, according to Karayalcin (1994), correspond to transatlantic migrations in the past centuries and to recent Gastarbeiter systems, respectively. Permanent migration means that young migrants leave their region of birth at the beginning of their industrious life and never return. So, this kind of migration involves the international movement of both labour and capital: the migrants invest their savings in the host region. Temporary migration is defined as the international movement of labour only. Agents spend their industrious life abroad and return to their region of birth when old and thereby invest their savings in that region.

\section{Permanent migration}

Permanent migration in a (two-period) overlapping-generations framework has been studied by Galor (1986). He shows that, in the absence of an immobile factor and PAYG-public pensions, there exists an incentive to migrate to the patient region, which means in our setup, the region with highest individual thriftiness. As migrants import their own capital stock (through their own savings), the wage of the host region remains above that of the source region, and therefore the entire young population of the impatient region will eventually migrate to the patient region. For their 
descendants as well as for the offspring of the native inhabitants of the host region it holds that they will reside in their region of birth. Therefore, only one region will be populated in the long run. It is straightforward that population ageing will not incite any migration flows given the distribution of agents in the (initial) equilibrium.

Analogously, in case of PAYG-public pensions, there will initially be an incentive to migrate to the region with relatively meager social-security arrangements (as this is the region with a relatively high capital stock). Immigration into this region has two opposite effects on the net wage. First, gross wages go down due to capital dilution. Second, the dependency ratio decreases because young people enter the region, which broadens the tax base. Depending on the type of pension scheme, this could imply a lower social security tax. In the other region, which faces emigration, gross wages go up due to capital thickening and the dependency ratio increases, which may increase the PAYG-tax. If, on the one hand, the dependency ratio-effect dominates the capital-dilution effects in the host country and the capital-thickening effect in the source country, then immigration has a positive effect on the net wage and emigration a negative effect. This immediately implies that the total young population of the region with the generous pension arrangements will instantaneously migrate to the region with the meager arrangements. On the other hand, if the capital effects are dominant, there will be a gradual transition eventually also leading to one populated region (the one with the relatively low PAYG-taxes) and one completely empty region. In both cases, the same equilibrium arises and ageing of (a part of) the population will therefore not cause any incentives for migration (see also Meier [1998]).

However, in the absence of a store of value and exogenously given wages, no unique steady-state equilibrium exists. There will also be an incentive to migrate to the region with relatively meager social-security arrangements. But if all agents have migrated to this region, the next-period young will have an incentive to migrate to the other (now empty) region because then they do not have to pay any PAYGtaxes, as there are no retirees present. The next generation of mobile young agents will make a similar deliberation. Since agents are gifted with perfect foresight, these future migration flows will put a strain on their incentives and multiple equilibria originate (see for example Von Hagen and Walz [1995]). Only the introduction of a fixed factor in production will assure the existence of a unique equilibrium because in that case the relative redundancy of (migrant) labour will result in an agglomeration disadvantage through a downward pressure on the (migrants') wages, thereby curbing the subsequent migration flows.

\section{Temporary migration}

With respect to temporary migration we restrict ourselves to the case of cross-border workers who supply labour in one region while they reside in the other. Furthermore, we assume that social-security taxes are residence based, i.e., agents are liable to pay 
taxes in their region of birth and not in the region in which they work. Only allowing for temporary migration, in the presence of PAYG-social security, results in the following initial (steady-state) migration flows. If both regions have equally generous social-security arrangements, agents will initially supply labour in their region of birth only and there is no cross-border labour mobility. If the regional pension schemes differ in their generosity, part of the labour force of the region with the relatively high pension benefits and taxes will cross the border and supply their labour abroad. This is due to capital being relatively scarce in the former region, implying relatively low wages. Cross-border labour mobility will equalise wages. So there will be no initial interregional wage differential. ${ }^{24}$ In the short run, population ageing will, irrespective of the relative size of the public pension schemes, induce a movement of cross-border workers to the ageing region as capital is relatively abundant. In the long run, the change in the number of cross-border workers depends on the relative size of the public pension scheme in the ageing region. If, on the one hand, the government of the ageing region (say the domestic one) runs a relatively generous social-security scheme (and therefore initially some domestic workers supply labour in the foreign region), the number of domestic cross-border workers will decrease because the relative size of the domestic region has decreased since we model ageing as a once-only negative shock to the domestic rate of population growth. The decrease in the size of the domestic region implies that the decision of one single domestic cross-border worker to supply labour abroad has a high positive impact on the domestic wage relative to the situation before the occurrence of ageing. So there will be less domestic cross-border workers. If, on the other hand, the domestic government runs a relatively meager public pension scheme (and therefore initially some foreign workers supply labour in the domestic region), the number of foreign cross-border workers will decrease as the capital stock of the domestic region has decreased (because of less domestic private savings). The decrease in the domestic capital stock implies that the decision of one single foreign cross-border worker to supply labour in the domestic region has a negative downward effect on the domestic wage relative to the situation before the occurrence of ageing. So the number of foreign cross-border workers will decrease.

\section{Proportional taxes}

If taxes are not collected in a lump-sum fashion but rather as a proportion of the gross wage, the intergenerational risk-sharing properties of the different types of pension schemes will change. With proportional taxation, taxes and benefits are respectively given by $\hat{\tau}_{t}=\tau_{t} w_{t}$ and $\hat{\eta}_{t}=\left(1+n_{t}\right) \tau_{t} w_{t}$. We show below that, in the absence of endogenous labour supply, proportional taxation only implies different risk-sharing

\footnotetext{
${ }^{24}$ Karayalcin (1994, Proposition 1, p.206) shows that temporary migration and international capital mobility are equivalent in the sense that at any instant, the rate of interest, wages, private savings and first-period and second-period consumption possibilities are the same under both settings. In particular, given the analysis of Karayalcin, it is straightforward to show that $\frac{\partial \mu_{t}}{\partial \tau}=\Psi\left(\frac{\partial k_{t}}{\partial \tau}\right)$, $\Psi^{\prime}(\cdot)<0, \forall t$, where $\mu_{t}$ denotes the number of domestic cross-border workers.
} 
properties compared to lump-sum taxation, but does not affect our main results.

\section{Defined Contribution}

Recall that for $D C$-schemes, the social-security tax is kept constant $\left(\tau_{t|\mathrm{DC}|}^{i}=\tau^{i}, \forall t\right)$. Therefore, the effects of domestic population ageing are only reflected in the benefit level, i.e.,

$$
\begin{aligned}
\frac{\partial \hat{\tau}_{t^{\mid \mathrm{DC}]}}^{i}}{\partial \pi} & =\tau^{i} \frac{\partial w_{t}}{\partial \pi}, \quad \forall t, \\
\frac{\partial \hat{\eta}_{t}^{D}[\mathrm{DC}]}{\partial \pi} & =\tau^{D} \frac{\partial w_{t}}{\partial \pi}-\tau^{D} w h_{t}, \quad \frac{\partial \hat{\eta}_{t}^{F}[\mathrm{DC}]}{\partial \pi}=\tau^{D} \frac{\partial w_{t}}{\partial \pi}, \quad \forall t .
\end{aligned}
$$

Contrary to lump-sum taxation, the PAYG-tax and benefit in the foreign region are affected by the demographic shock in the other region through capital thickening. Comparing (13') to (15) shows that both under a $D C$-scheme with proportional taxation and under a $F R$-scheme with lump-sum taxation, the effects of ageing caused by capital thickening are shared by the current old and young. The dependency-ratio effect is in the former case only felt by the pensioners, and in the latter case by the tax payers.

\section{Defined Benefit}

In case of $D B$-schemes, the level of the public pension benefit is kept constant $\left(\hat{\eta}_{t^{\mid \mathrm{DB}} \mid}^{i}=\right.$ $\left.\hat{\eta}_{|\mathrm{DB}|}^{i}, \forall t\right)$. So, the effects of domestic population ageing are only reflected in the PAYG-tax, i.e.,

$$
\frac{\partial \hat{\eta}_{t}^{i}{ }_{t \mathrm{DB} \mid}}{\partial \pi}=0, \quad \frac{\partial \hat{\tau}_{t}^{D}[\mathrm{DB} \mid}{\partial \pi}=\tau^{D} \frac{\partial w_{t}}{\partial \pi}-\tau^{D} w h_{t}, \frac{\partial \hat{\tau}_{t}^{F}{ }^{|\mathrm{DB}|} \mid}{\partial \pi}=\tau^{F} \frac{\partial w_{t}}{\partial \pi}, \quad \forall t .
$$

Comparing (14') to (14) shows that in case of proportional taxation, both the dependencyratio effect and the capital-thickening effect are at the expense of the tax-paying generation, as total tax revenues have to be constant.

\section{Fixed Replacement Ratio}

If the level of the PAYG-benefit is a constant fraction $\varphi^{i}$ of the gross wage, then $\hat{\eta}_{t}^{i[\mathrm{FR}]}=$ $\varphi^{i} w_{t}$. A balanced government budget implies that the social-security tax is $\hat{\tau}_{t^{[\mathrm{FR}]}}^{i}=$ $\frac{\varphi^{i}}{1+n_{t}^{i}}$. The effects of domestic population ageing on the social-security arrangements are now given by

$$
\frac{\partial \hat{\tau}_{t}^{D}[\mathrm{FR}]}{\partial \pi}=-\varphi^{D} h_{t}, \quad \frac{\partial \hat{\tau}_{t \mid \mathrm{FR}]}^{F}}{\partial \pi}=\frac{\partial \hat{\eta}_{t}^{i} t^{[\mathrm{FR}]}}{\partial \pi}=0, \quad \forall t .
$$

A comparison of $\left(15^{\prime}\right)$ with (14) shows that a $F R$-scheme with proportional taxation is equivalent to a $D B$-scheme with lump-sum taxation (with $\eta^{D}=\varphi^{D}$ ). 


\section{International differences in the design of pension schemes}

We restricted ourselves to cases where both regions have the same type of pension scheme. For any domestic institutional design, it makes no difference for the effects of (domestic) ageing on the capital-labour ratio whether the foreign government runs a $D C$ - or $D B$-scheme, as the foreign population size is assumed to be constant over time. If a $F R$-scheme is superimposed on the foreign region, then (given Assumption II) the effects of domestic ageing on the capital-labour ratio are curbed relative to any other type of foreign pension scheme. Suppose, for example, that domestic ageing implies - ceteris paribus - an increase of the capital-labour ratio. This leads to a higher wage and, in case of a $F R$-scheme in the foreign region, to an increase of the generosity of the foreign social-security scheme. This has, given dynamic efficiency, a negative effect on foreign private savings and thereby on the increase of the capitallabour ratio.

\section{Concluding Remarks}

In the light of further European unification and global integration, asymmetric demographic shocks will increasingly bring about international implications. Atop intergenerational risk-sharing, international risk-sharing therefore deserves more attention. In this paper, we analysed the effects of asymmetric demographic shocks in a two-region framework with perfectly mobile capital. We found that population ageing in one region causes several international spillover effects. The magnitude of these spillovers depends on regional differences in individual thriftiness and the design and generosity of social-security arrangements. Whether the ageing region is a net lender or borrower turned out to be of significant importance for both the short-run dynamics and the long-run effects. It would be interesting to expand our analysis to investigate capital market imperfections, as described by Gordon and Bovenberg (1996), and international policy coordination (see Pemberton [1999]) or fiscal competition between for example the member states of the European Union through the introduction of taxes on capital income. Furthermore, allowing for a multi-period framework and a world with a larger number of regions which differ in the degree and the moment of ageing could help gaining more insight into the effects of upcoming demographic shocks on the world economy. Another extension would be to explicitly take into account that the relatively more numerous elderly may become a more powerful actor in the political arena. 


\section{Appendix}

\section{A The linearised model}

This part of the Appendix describes the linearised relations of the model. The changes in the wage and the rate of interest are given by

$$
\begin{aligned}
\frac{\partial w_{t}}{\partial \pi} & =-f^{\prime \prime}(k) k \frac{\partial k_{t}}{\partial \pi} \\
\frac{\partial r_{t}}{\partial \pi} & =f^{\prime \prime}(k) \frac{\partial k_{t}}{\partial \pi} .
\end{aligned}
$$

The change in private savings is now given by

$$
\begin{aligned}
\frac{\partial s_{t}^{i}}{\partial \pi}= & \frac{1}{2+\rho^{i}}\left(\frac{\partial w_{t}}{\partial \pi}-\frac{\partial \tau_{t}^{i}}{\partial \pi}\right)- \\
& \frac{1+\rho^{i}}{2+\rho^{i}}\left(\frac{1}{1+r} \frac{\partial \tau_{t+1}^{i}}{\partial \pi}+\frac{\tau^{i}}{1+r} h_{t+1}-\frac{\tau^{i}}{(1+r)^{2}} \frac{\partial r_{t+1}}{\partial \pi}\right) .
\end{aligned}
$$

Consumption possibilities when young and old change as follows,

$$
\begin{aligned}
\frac{\partial c_{t}^{i}}{\partial \pi} & =\frac{\partial w_{t}}{\partial \pi}-\frac{\partial \tau_{t}^{i}}{\partial \pi}-\frac{\partial s_{t}^{i}}{\partial \pi} \\
\frac{\partial z_{t+1}^{i}}{\partial \pi} & =(1+r) \frac{\partial s_{t}^{i}}{\partial \pi}+s \frac{\partial r_{t+1}}{\partial \pi}+\frac{\partial \tau_{t+1}^{i}}{\partial \pi}+\tau^{i} h_{t+1} .
\end{aligned}
$$

The change in lifetime utility is now given by

$$
\frac{\partial U_{t}^{i}}{\partial \pi}=\frac{1}{c^{i}} \frac{\partial c_{t}^{i}}{\partial \pi}+\frac{1}{1+\rho^{i}} \frac{1}{z^{i}} \frac{\partial z_{t+1}^{i}}{\partial \pi} .
$$

The linearised version of the capital-accumulation equation reads

$$
\frac{\partial s_{t}^{D}}{\partial \pi}+\frac{\partial s_{t}^{F}}{\partial \pi}+\left(s^{D}-k\right) H_{t}=2 \frac{\partial k_{t+1}}{\partial \pi}+k h_{t+1} .
$$

As in the (initial) steady state, capital accumulation is given by $s^{D}+s^{D}=2 k$, we get $\left(s^{D}-k\right)=\frac{1}{2}\left(s^{D}-s^{F}\right)$. The following economic relations, the balance of trade and the current account, provide additional information of the economic interaction between the regions. The balance of trade $\left(B T_{t}^{i}\right)$ for region $i$ at time $t$ is given by

$$
B T_{t}^{i}=N_{t}^{i} f\left(k_{t}\right)-N_{t}^{i} c_{t}^{i}-N_{t-1}^{i} z_{t}^{i}-\left(K_{t+1}^{i}-K_{t}^{i}\right),
$$

where $K_{t}^{i}$ is the capital stock of region $i$ at time $t$. Per inhabitant of region $i$ the balance of trade reads

$$
\frac{B T_{t}^{i}}{N_{t}^{i}} \equiv b t_{t}^{i}=f\left(k_{t}\right)-c_{t}^{i}-\frac{z_{t}^{i}}{1+n_{t}^{i}}-\left(\left(1+n_{t}^{i}\right) k_{t+1}-k_{t}\right)
$$


The current account $\left(C U A_{t}^{i}\right)$ is defined as the balance of trade plus the returns on investments abroad, i.e., $C U A_{t}^{i}=B T_{t}^{i}+r_{t}\left(S_{t-1}^{i}-K_{t}\right)$, with $S_{t-1}^{i}$ the aggregate savings of region $i$ at time $t-1$. Per inhabitant the current account is

$$
c u a_{t}^{i} \equiv \frac{C U A_{t}^{i}}{N_{t}^{i}}=b t_{t}^{i}+r_{t}\left(\frac{s_{t-1}^{i}}{1+n_{t}^{i}}-k_{t}\right)
$$

Using the fact that $f\left(k_{t}\right)=w_{t}+r_{t} k_{t}$ (constant returns to scale), we can write (A.10) as

$$
c u a_{t}^{i}=s_{t}^{i}-\frac{s_{t-1}^{i}}{1+n_{t}^{i}}-\left(\left(1+n_{t+1}^{i}\right) k_{t+1}-k_{t}\right) .
$$

The linearised versions of (A.9) and (A.11) read respectively

$$
\begin{aligned}
\frac{\partial b t_{t}^{i}}{\partial \pi} & =f^{\prime}\left(k_{t}\right) \frac{\partial k_{t}}{\partial \pi}-\frac{\partial c_{t}^{i}}{\partial \pi}-\frac{\partial z_{t}^{i}}{\partial \pi}+z^{i} g_{t}^{i}-\frac{\partial k_{t+1}}{\partial \pi}-k g_{t+1}^{i}+\frac{\partial k_{t}}{\partial \pi}, \\
\frac{\partial c u a_{t}^{i}}{\partial \pi} & =\frac{\partial s_{t}^{i}}{\partial \pi}-\frac{\partial s_{t-1}^{i}}{\partial \pi}+s^{i} g_{t}^{i}-\frac{\partial k_{t+1}}{\partial \pi}-k g_{t+1}^{i}+\frac{\partial k_{t}}{\partial \pi},
\end{aligned}
$$

where $g_{t}^{D}=h_{t}$ and $g_{t}^{F}=0, \forall t$. As in our world there is no long-run population growth, which implies $c u a^{D}=c u a^{F}=0$, and because it only consists of two regions, it holds by definition that $c u a_{t}^{D}+c u a_{t}^{F}=0, \forall t$ and thereby $\frac{\partial c u a_{t}^{D}}{\partial \pi}=-\frac{\partial c u a_{t}^{F}}{\partial \pi}, \forall t$.

\section{B Stability conditions}

For the different pension schemes presented in Section 4 the parameters of the linear first-order difference equation (16), which has been rewritten here for convenience,

$$
\frac{\partial k_{t+1}[\mathrm{x}]}{\partial \pi}=\alpha_{[\mathrm{X}]} \frac{\partial k_{t}[\mathrm{x}]}{\partial \pi}+\beta_{[\mathrm{DC}]} h_{t}+\gamma_{[\mathrm{DC}]} h_{t+1}+\delta_{[\mathrm{DB}]}\left(\tau^{F}-\tau^{D}\right) H_{t},
$$

are given by (where $\left.\Phi=2(2+\rho)(1+r)^{2}-\left(\tau^{D}+\tau^{F}\right)(1+\rho) f^{\prime \prime}(k)>0\right)$

$$
\begin{aligned}
\alpha_{[\mathrm{DC}]} & =\alpha_{[\mathrm{DB}]}=-\frac{2 f^{\prime \prime}(k) k(1+r)^{2}}{\Phi} \in(0,1), \\
\beta_{[\mathrm{DC}]} & =0, \\
\gamma_{[\mathrm{DC}]} & =-\frac{\left(k(2+\rho)(1+r)+\tau^{D}(1+\rho)\right)(1+r)}{\Phi}<0, \\
\delta_{[\mathrm{DC}]} & =\delta_{[\mathrm{DB}]}=\frac{(2+\rho+r)(1+r)}{2 \Phi}>0, \\
\beta_{[\mathrm{DB}]} & =\frac{\tau^{D}(1+r)^{2}}{\Phi}>0, \\
\gamma_{[\mathrm{DB}]} & =-\frac{k(2+\rho)(1+r)^{2}}{\Phi}<0, \\
\alpha_{[\mathrm{FR}]} & =\frac{f^{\prime \prime}(k) k\left(\varphi^{D}+\varphi^{F}-2\right)(1+r)^{2}}{\Phi-(1+\rho) f^{\prime \prime}(k) k\left(\varphi^{D}+\varphi^{F}\right)(1+r)} \in(0,1),
\end{aligned}
$$




$$
\begin{aligned}
\beta_{\mid \mathrm{FR}]} & =\frac{\tau^{D}(1+r)^{2}}{\Phi-(1+\rho) f^{\prime \prime}(k) k\left(\varphi^{D}+\varphi^{F}\right)(1+r)}>0, \\
\gamma_{\mid \mathrm{FR}]} & =-\frac{k(2+\rho)(1+r)^{2}}{\Phi-(1+\rho) f^{\prime \prime}(k) k\left(\varphi^{D}+\varphi^{F}\right)(1+r)}<0, \\
\delta_{[\mathrm{FR}]} & =\frac{(2+\rho+r)(1+r)}{2\left(\Phi-(1+\rho) f^{\prime \prime}(k) k\left(\varphi^{D}+\varphi^{F}\right)(1+r)\right)}>0 .
\end{aligned}
$$

Using $\left(\right.$ A.15) and (A.21) we get $0<\alpha_{|\mathrm{FR}|}<\alpha_{|\mathrm{DC}|}=\alpha_{|\mathrm{DB}|}<-\frac{1}{2} f^{\prime \prime}(k) k$. Galor and Ryder (1989) proof that, given our assumptions with respect to the production function and our specification of the utility function, $-\frac{1}{2} f^{\prime \prime}(k) k \in(0,1)$. So, irrespective of the type of pension scheme, the (initial) steady state is locally stable.

Assumption II. As mentioned in the main text, Assumption II implies a positive upper bound for the initial generosity of the regional social-security arrangements. For a $D C$ - or a $D B$-scheme this assumption boils down to

$$
\tau^{i}<\frac{(1+r)^{2}}{1+\rho} k
$$

For a $F R$-scheme we get

$$
\varphi^{i}<\frac{(1+r)^{2}}{(1+\rho) w+(2+r+\rho)(1+r) k} k .
$$

Combining (A.25) and (A.26) gives

$$
\tau^{i}<\min \left[\frac{(1+r)^{2}}{1+\rho} k, \frac{w(1+r)^{2}}{(1+\rho) w+(2+r+\rho)(1+r) k} k\right] .
$$

The initial change in the domestic net wage. In case of a DB-scheme, the net wage initially increases (decreases) $\left(\frac{\partial\left[w_{0}-\tau_{0}^{D}\right]}{\partial \pi} \gtrless 0\right)$ if $\tau^{D} \lessgtr-f^{\prime \prime}(k) \frac{k^{2}}{2}$. In case of a $F R$-scheme, the net wage initially increases (decreases) $\left(\frac{\partial\left[w_{0}-\tau_{0}^{D}\right]}{\partial \pi} \gtrless 0\right)$ if $\frac{\varphi^{D}}{1-\varphi^{D}} \lessgtr$ $-f^{\prime \prime}(k) \frac{k^{2}}{2 w}$.

\section{The small open economy}

If we consider a small open economy instead of (two) large open economies, the interest rate is exogenously determined at the world capital markets $\left(r_{t}=r, \forall t\right)$ and consequently both the capital-labour ratio and the wage are constant,

$$
\begin{aligned}
k & =f^{\prime-1}(r), \\
w & =f(k)-f^{\prime}(k) k .
\end{aligned}
$$


Conform (6), savings are then given by

$$
s_{t}^{S O E_{[\mathrm{X}]}}=\frac{1}{2+\rho}\left(w-\tau_{t}^{S O E_{[\mathrm{x}]}}\right)-\frac{1+\rho}{2+\rho} \frac{\left.\eta_{t+1}^{S O E} \mid \mathrm{x}\right]}{1+r},
$$

where the superscript $S O E$ refers to the small-open economy case. If the population of the small open economy ages relative to the rest of the world, and again, ageing is modeled as an unexpected or expected one-period decrease in the rate of population growth $\left(h_{t}^{\prime}<0, t^{\prime}=0, t^{*}\right)$, the marginal change in the level of private savings for a $D C$-scheme is given by

$$
\frac{\partial s_{t^{\prime}}^{S O E}[\mathrm{DC}]}{\partial \pi}=-\frac{1+\rho}{2+\rho} \frac{\tau^{S O E}}{1+r} h_{t^{\prime}+1}
$$

For a $D B$ - and $F R$-scheme, the change in private savings reads

$$
\frac{\partial s_{t^{\prime}}^{S O E}[\mathrm{Y}]}{\partial \pi}=\frac{\tau^{S O E}}{2+\rho} h_{t^{\prime}}, \quad Y=D B, F R
$$

Because a current demographic shock does not affect the current PAYG-tax if a $D C$-scheme is in place and the next-period dependency ratio is at its old level again, the next-period pension benefit does not change. Therefore, if ageing is unexpected, savings do not react and remain at their initial steady-state level, as can be seen from (A.31). On the other hand, if ageing is expected, the young alive at the moment before the shock occurs, anticipate the decrease in their next-period benefits by an increase of their savings.

In case of a $D B$ - or $F R$-scheme, both expected and unexpected ageing only cause a change in the level of private savings at the time the shock occurs (see (A.32)). This is due to benefits remaining unaltered whereas the dependency-ratio effect is completely reflected in an increase of the social-security tax, resulting in a decrease of their net wage and thereby lower savings. Therefore, population ageing in a small open economy is merely reflected in a temporary change of the current account. 


\section{References}

[1] Buiter, W.H. (1981) "Time Preference and International Lending and Borrowing in an Overlapping-Generations Model" Journal of Political Economy 89: 769797.

[2] Casarico, A. (1999) Pension Systems in Open Economy Nuffield College Working Paper 1999-W10, Oxford.

[3] Diamond, P.A. (1965) "National Debt in a Neoclassical Growth Model" American Economic Review 55: 1126-1150.

[4] Feldstein, M. (1974) "Social Security, Induced Retirement, and Aggregate Capital Accumulation" Journal of Political Economy 82: 905-926.

[5] Feldstein, M. (1996a) "The Missing Piece in Policy Analysis: Social Security Reform" American Economic Review, Papers and Proceedings 86: 1-14.

[6] Feldstein, M. (1996b) "Social Security and Saving: New Time Series Evidence" National Tax Journal 49: 151-164.

[7] Galor, O. (1986) "Time Preference and International Labor Migration" Journal of Economic Theory 38: 1-18.

[8] Galor, O. and H.E. Ryder (1989) "Existence, Uniqueness, and Stability of Equilibrium in an Overlapping-Generations Model with Productive Capital" Journal of Economic Theory 49: 360-375.

[9] Geide-Stevenson, D. (1998) "Social Security Policy and International Labor and Capital Mobility" Review of International Economics 6: 407-416.

[10] Gordon, R.H. and A.L. Bovenberg (1996) "Why Is Capital So Immobile Internationally? Possible Explanations and Implications for Capital Income Taxation" Journal of Public Economics 86: 1057-1075.

[11] Ihori, T. (1996) Public Finance in an Overlapping Generations Economy London: MacMillan Press.

[12] Hagen, J., von and U. Walz (1994) "Social Security and Migration in an Ageing Europe" In Eichengreen, B., J. Frieden and J. von Hagen (eds.) Politics and Institutions in an Integrated Europe, Springer, Berlin Heidelberg: 177-192.

[13] Hayashi, F. (1982) “Tobin's Marginal $q$ and Average $q$ : A Neoclassical Interpretation" Econometrica 50: 213-224.

[14] Judd, K.L. (1982) "An Alternative to Steady-State Comparisons in Perfect Foresight Models" Economics Letters 10: 55-59. 
[15] Karayalcin, C. (1994) "Temporary and Permanent Migration with and without an Immobile Factor" Journal of Development Economics 43: 197-215.

[16] Michel, P. and D. de la Croix (2000) "Myopic and Perfect Foresight in the OLG Model" Economics Letters 67: 53-60.

[17] Meier, V. (1998) "Time Preference, International Migration, and Social Security" Discussion Paper 15, Martin-Luther-University Halle-Wittenberg.

[18] Organisation for Economic Cooperation and Development (1999) OECD Economic Outlook No. 64, Paris.

[19] Pemberton, J. (1999) "Social Security: National Policies with International Implications" Economic Journal 109: 492-508.

[20] Shiller, R.J. (1999) "Social Security and Institutions for Intergenerational, Intragenerational, and International Risk-Sharing" Carnegie-Rochester Conference Series on Public Policy 50: 165-204.

[21] United Nations (1998) World Population Prospects: The 1998 Revision, New York. 